Cochrane Database of Systematic Reviews

\title{
Botulinum toxin type A versus botulinum toxin type B for cervical dystonia (Review)
}

Duarte GS, Castelão M, Rodrigues FB, Marques RE, Ferreira J, Sampaio C, Moore AP, Costa J

Duarte GS, Castelão M, Rodrigues FB, Marques RE, Ferreira J, Sampaio C, Moore AP, Costa J.

Botulinum toxin type A versus botulinum toxin type B for cervical dystonia.

Cochrane Database of Systematic Reviews 2016, Issue 10. Art. No.: CD004314.

DOI: 10.1002/14651858.CD004314.pub3.

www.cochranelibrary.com 
TABLE OF CONTENTS

ABSTRACT 1

PLAIN LANGUAGE SUMMARY

SUMMARY OF FINDINGS

BACKGROUND

OBJECTIVES

METHODS

Figure 1.

RESULTS

Figure 2.

Figure 3.

Figure 4.

DISCUSSION

AUTHORS' CONCLUSIONS

ACKNOWLEDGEMENTS

REFERENCES

CHARACTERISTICS OF STUDIES

DATA AND ANALYSES

Analysis 1.1. Comparison 1 Botulinum toxin type A versus botulinum toxin type B, Outcome 1 Overall cervical dystonia improvement as assessed with validated scales: change from baseline to week 4.

Analysis 1.2. Comparison 1 Botulinum toxin type $A$ versus botulinum toxin type B, Outcome 2 Cervical dystonia associated severity: change from baseline to week 2-4 as assessed with validated scales.

Analysis 1.3. Comparison 1 Botulinum toxin type A versus botulinum toxin type B, Outcome 3 Cervical dystonia associated disability: change from baseline to week 2-4 as assessed with validated scales.

Analysis 1.4. Comparison 1 Botulinum toxin type A versus botulinum toxin type B, Outcome 4 Proportion of participants with adverse events.

Analysis 1.5. Comparison 1 Botulinum toxin type A versus botulinum toxin type B, Outcome 5 Subjective change as assessed by the patient at week 4 .

Analysis 1.6. Comparison 1 Botulinum toxin type A versus botulinum toxin type B, Outcome 6 Subjective change as assessed by clinician at week 4 .

Analysis 1.7. Comparison 1 Botulinum toxin type A versus botulinum toxin type B, Outcome 7 Cervical dystonia associated pain: change from baseline to week 2-4 as assessed with validated scales.

Analysis 1.8. Comparison 1 Botulinum toxin type A versus botulinum toxin type B, Outcome 8 Adverse event: sore throat/dry mouth.

Analysis 1.9. Comparison 1 Botulinum toxin type A versus botulinum toxin type B, Outcome 9 Adverse event: dysphagia. ...... Analysis 1.10. Comparison 1 Botulinum toxin type A versus botulinum toxin type B, Outcome 10 Adverse event: injection site pain.

ADDITIONAL TABLES

APPENDICES

WHAT'S NEW

HISTORY

CONTRIBUTIONS OF AUTHORS

DECLARATIONS OF INTEREST

SOURCES OF SUPPORT

DIFFERENCES BETWEEN PROTOCOL AND REVIEW

INDEX TERMS 
[Intervention Review]

\section{Botulinum toxin type A versus botulinum toxin type B for cervical dystonia}

Gonçalo S Duarte1,2a , Mafalda Castelão1,2b, Filipe B Rodrigues ${ }^{1,2 c}$, Raquel E Marques ${ }^{1,2 d}$, Joaquim Ferreira1,2, Cristina Sampaio ${ }^{3}$, Austen P Moore 4 , João Costa1,2

1Laboratório de Farmacologia Clínica e Terapêutica, Faculdade de Medicina de Lisboa, Lisboa, Portugal. ${ }^{2}$ Clinical Pharmacology Unit, Instituto de Medicina Molecular, Lisboa, Portugal. ${ }^{3} \mathrm{CHDI}$ Foundation, Princeton, NJ, USA. ${ }^{4}$ The Walton Centre NHS Foundation Trust, Liverpool, UK

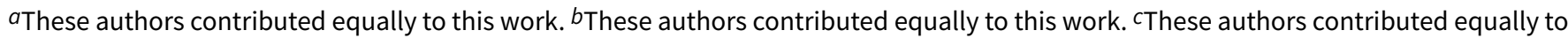
this work. ${ }^{d}$ These authors contributed equally to this work

Contact: João Costa, Clinical Pharmacology Unit, Instituto de Medicina Molecular, Av. Prof. Egas Moniz, Lisboa, 1649-028, Portugal. jncosta@medicina.ulisboa.pt.

Editorial group: Cochrane Movement Disorders Group.

Publication status and date: New search for studies and content updated (conclusions changed), published in Issue 10, 2016.

Citation: Duarte GS, Castelão M, Rodrigues FB, Marques RE, Ferreira J, Sampaio C, Moore AP, Costa J. Botulinum toxin type A versus botulinum toxin type B for cervical dystonia. Cochrane Database of Systematic Reviews 2016, Issue 10. Art. No.: CD004314. DOI: 10.1002/14651858.CD004314.pub3.

Copyright @ 2016 The Cochrane Collaboration. Published by John Wiley \& Sons, Ltd.

\section{A B S T R A C T}

\section{Background}

This is an update of a Cochrane review first published in 2003. Cervical dystonia is the most common form of focal dystonia and is a disabling disorder characterised by painful involuntary head posturing. There are two available formulations of botulinum toxin, with botulinum toxin type $\mathrm{A}(\mathrm{Bt} \mathrm{A})$ usually considered the first line therapy for this condition. Botulinum toxin type $\mathrm{B}(\mathrm{BtB})$ is an alternative option, with no compelling theoretical reason why it might not be as- or even more effective - than BtA.

\section{Objectives}

To compare the efficacy, safety and tolerability of botulinum toxin type $A(B t A)$ versus botulinum toxin type $B$ (BtB) in people with cervical dystonia.

\section{Search methods}

To identify studies for this review we searched the Cochrane Movement Disorders Group Trials Register, the Cochrane Central Register of Controlled Trials (CENTRAL), MEDLINE, Embase, reference lists of articles and conference proceedings. All elements of the search, with no language restrictions, were last run in October 2016.

\section{Selection criteria}

Double-blind, parallel, randomised, placebo-controlled trials (RCTs) comparing BtA versus BtB in adults with cervical dystonia.

\section{Data collection and analysis}

Two independent authors assessed records, selected included studies, extracted data using a paper pro forma, and evaluated the risk of bias. We resolved disagreements by consensus or by consulting a third author. We performed meta-analyses using the random-effects model, for the comparison BtA versus BtB to estimate pooled effects and corresponding $95 \%$ confidence intervals (95\% Cl). No prespecified subgroup analyses were carried out. The primary efficacy outcome was improvement on any validated symptomatic rating scale, and the primary safety outcome was the proportion of participants with adverse events. 


\section{Main results}

We included three RCTs, all new to this update, of very low to low methodological quality, with a total of 270 participants.

Two studies exclusively enrolled participants with a known positive response to BtA treatment. This raises concerns of population enrichment, with a higher probability of benefit from BtA treatment. None of the trials were free of for-profit bias, nor did they provide information regarding registered study protocols. All trials evaluated the effect of a single Bt treatment session, and not repeated treatment sessions, using doses from $100 \mathrm{U}$ to $250 \mathrm{U}$ of BtA (all onabotulinumtoxinA, or Botox, formulations) and $5000 \mathrm{U}$ to $10,000 \mathrm{U}$ of BtB (rimabotulinumtoxinB, or Myobloc/Neurobloc).

We found no difference between the two types of botulinum toxin in terms of overall efficacy, with a mean difference of -1.44 ( $95 \% \mathrm{Cl}-3.58$ to 0.70 ) points lower on the Toronto Western Spasmodic Torticollis Rating Scale (TWSTRS) for BtB-treated participants, measured at two to four weeks after injection. The proportion of participants with adverse events was also not different between $B t A$ and $B t B$ (BtB versus $B$ tA risk ratio (RR) $1.40 ; 95 \% \mathrm{Cl} 1.00$ to 1.96). However, when compared to $B t A$, treatment with $B t B$ was associated with an increased risk of one adverse events of special interest, namely treatment-related sore throat/dry mouth (BtB versus $\mathrm{BtA} \mathrm{RR}$ of $4.39 ; 95 \% \mathrm{Cl} 2.43$ to 7.91 ). Treatment-related dysphagia (swallowing difficulties) was not different between BtA and BtB (RR 2.89; $95 \% \mathrm{Cl} 0.80$ to 10.41 ). The two types of botulinum toxin were otherwise clinically non-distinguishable in all the remaining outcomes.

\section{Authors' conclusions}

The previous version of this review did not include any trials, since these were still ongoing at the time. Therefore, with this update we are able to change the conclusions of this review. There is low quality evidence that a single treatment session of BtA (specifically onabotulinumtoxin $A$ ) and a single treatment session of $B t B$ (rimabotulinumtoxin $B$ ) are equally effective and safe in the treatment of adults with certain types of cervical dystonia. Treatment with BtB appears to present an increased risk of sore throat/dry mouth, compared to BtA. Overall, there is no clinical evidence from these single-treatment trials to support or contest the preferential use of one form of botulinum toxin over the other.

\section{PLAIN LANGUAGE SUMMARY}

\section{A comparison of botulinum toxin type A versus botulinum toxin type B for involuntary positioning of the head, or cervical dystonia}

\section{The review question}

We reviewed the evidence about the effect of botulinum toxin type $A(B t A)$ compared to botulinum toxin type $B$ (BtB) in people with involuntary positioning of the head, or cervical dystonia. This is an update of a previous Cochrane Review and we assessed the effectiveness (reduction in severity, disability and pain) and safety of BtA versus BtB in cervical dystonia.

\section{Background}

Cervical dystonia, also called spasmodic torticollis, is a disease that causes undesired, uncontrollable, often painful, abnormal placement of the head. It is a relatively uncommon condition (affecting 57 to 280 people per million) that can be very disabling and can affect a person's quality of life negatively. In most cases the cause is unknown and no cure exists. Since cervical dystonia is normally a long-term disease it requires long-term treatment.

Botulinum toxin (Bt) is a powerful, natural chemical that can cause severe paralysis (an inability to move in the part of the body where it is applied) in animals and humans. It can also be used to treat many conditions, in particular those with involuntary muscle contractions, such as cervical dystonia. Bt is delivered by injections into the muscles that contract to produce the disease. There are different types of $\mathrm{Bt}$, not all are available for treating health conditions. BtA is typically the first-used treatment in cervical dystonia, but botulinum toxin type $B(B t B)$ is an alternative option. The relative strength of each Bt formulation is variable, and the cost for 200 units varies from GBP 198 to GBP 308.

\section{Study characteristics}

We performed a rigorous search of the medical literature in October 2016 and found three studies that compared a single treatment session of BtA with BtB. These studies included a total of 270 participants, with on average a moderate disease impairment. The participants remained in the studies for a short period of time - between 16 and 20 weeks after the treatment. The average age of people in the studies was 53.3 years, and they had had cervical dystonia for an average of 6.6 to 7.9 years before taking part in the trials. Most, $63.3 \%$, of the people in the studies were women. All three of the studies were funded by drug manufacturers with possible interests in the results of the studies.

\section{Key results}

The results show little or no difference between $B t A$ and $B t B$ in the main measures of overall improvement and safety, including the total number of adverse (unwanted or harmful) events. There was also little or no difference between BtA and BtB in the self-evaluations reported by the study participants. Based on the results we would expect that, out of 1000 people with cervical dystonia treated with $B t B$, there would be 362 more people who experience dry mouth/sore throat compared to 1000 people treated with BtA. The studies which 
looked at the duration of effect showed little or no difference between BtA and BtB. None of the studies examined the impact of either Bt on quality of life.

\section{Quality of the evidence}

All of the studies included participants that were different to the average person who suffers from cervical dystonia. To be included participants had to have a history of successful treatment with Bt. People with certain types of cervical dystonia, in particular the forms that make the head turn backward or forward, were not allowed to participate in the studies.

Not enough participants were included across the studies for us to be completely confident in the results for the total number of adverse events, the self-reported evaluations by participants or the pain assessment.

The quality of the evidence for overall improvement and total number of adverse events was low. The quality of the evidence for more sore throat/dry mouth in people receiving BtB is moderate. The quality of the evidence where participants gave their self-assessments is low.

No definite conclusions can be drawn regarding overall safety and long-term utility of BtA compared to BtB in cervical dystonia. 


\section{SUMMARY OF FINDINGS}

\section{Summary of findings for the main comparison. Botulinum toxin type A versus botulinum toxin type B for adults with cervical dystonia}

\section{Botulinum toxin type A compared to botulinum toxin type B for adults with cervical dystonia}

Patient or population: adults with cervical dystonia

Settings: hospital-based, movement disorders clinics

Intervention: botulinum toxin type A

Comparison: botulinum toxin type $B$

\begin{tabular}{|c|c|c|c|c|c|c|}
\hline \multirow[t]{2}{*}{ Outcomes } & \multirow{2}{*}{$\begin{array}{l}\text { Relative effect } \\
(95 \% \mathrm{Cl})\end{array}$} & \multicolumn{3}{|c|}{ Anticipated absolute effects ${ }^{\star}(95 \% \mathrm{Cl})$} & \multirow{2}{*}{$\begin{array}{l}\text { Quality of the evi- } \\
\text { dence } \\
\text { (GRADE) }\end{array}$} & \multirow[t]{2}{*}{ What happens } \\
\hline & & $\begin{array}{l}\text { With botu- } \\
\text { linum toxin } \\
\text { type } A\end{array}$ & $\begin{array}{l}\text { With botu- } \\
\text { linum toxin } \\
\text { type B }\end{array}$ & Difference & & \\
\hline $\begin{array}{l}\text { Overall cervical dystonia improve- } \\
\text { ment: change from baseline to week } \\
4 \text { assessed with TWSTRS total score } \\
\text { Scale (range, } 0 \text { to } 85 \text {; more is worst) } \\
\text { № of participants: } 231 \\
\text { (2 RCTs) }\end{array}$ & - & $\begin{array}{l}\text { 9.1 TWSTRS } \\
\text { units decrease }\end{array}$ & $\begin{array}{l}\text { 10.5 TWSTRS } \\
\text { units decrease }\end{array}$ & $\begin{array}{l}\text { The mean change } \\
\text { from baseline was } 1.44 \\
\text { TWSTRS units higher ( } 0.7 \\
\text { lower to } 3.58 \text { higher) in } \\
\text { the BtB group compared } \\
\text { to the BtA group }\end{array}$ & $\begin{array}{l}\oplus \oplus \ominus \ominus \\
\text { LOW 1, } 2 \\
\text { Due to study limita- } \\
\text { tions and impreci- } \\
\text { sion }\end{array}$ & $\begin{array}{l}\text { There may be little or } \\
\text { no difference in the } \\
\text { overall cervical dysto- } \\
\text { nia improvement }\end{array}$ \\
\hline $\begin{array}{l}\text { Participants with adverse events } \\
\text { № of participants: } 111 \\
\text { (1 RCT) }\end{array}$ & $\begin{array}{l}\text { RR } 1.40 \\
\text { (1.00 to } 1.96)\end{array}$ & $47.3 \%$ & $66.2 \%$ & $\begin{array}{l}18.9 \% \text { more adverse } \\
\text { events } \\
\text { ( } 0 \text { fewer to } 45.4 \text { more) }\end{array}$ & $\begin{array}{l}\oplus \oplus \ominus \ominus \\
\text { LOW } \mathbf{3} \\
\text { Due to imprecision }\end{array}$ & $\begin{array}{l}\text { There may be little or } \\
\text { no difference in the } \\
\text { risk of adverse events }\end{array}$ \\
\hline $\begin{array}{l}\text { Subjective change as assessed by } \\
\text { the patient at week } \mathbf{4} \\
\text { assessed with: PGA } \\
\text { Scale (range, - } 4 \text { to } 4 \text {; more is worst) } \\
\text { № of participants: } 138 \\
\text { (1 RCT) }\end{array}$ & - & $\begin{array}{l}\text { 1.6 PGA units } \\
\text { decrease }\end{array}$ & $\begin{array}{l}\text { 1.4 PGA units } \\
\text { decrease }\end{array}$ & $\begin{array}{l}\text { The mean subjective } \\
\text { change in the BtB group } \\
\text { was } 0.2 \text { PGA units lower } \\
\text { ( } 0.17 \text { lower to } 0.57 \text { high- } \\
\text { er) compared to the BtA } \\
\text { group }\end{array}$ & $\begin{array}{l}\oplus \oplus \ominus \ominus \\
\text { LOW 2, } 4 \\
\text { Due to study limita- } \\
\text { tions and impreci- } \\
\text { sion }\end{array}$ & $\begin{array}{l}\text { There may be little or } \\
\text { no difference in sub- } \\
\text { jective assessment }\end{array}$ \\
\hline $\begin{array}{l}\text { Cervical dystonia associated pain: } \\
\text { change from baseline to week 2-4 } \\
\text { assessed with TWSTRS pain sub- } \\
\text { scale } \\
\text { Scale (range, } 0 \text { to } 20 \text {; more is worst) } \\
\text { № of participants: } 251 \\
\text { (3 RCTs) }\end{array}$ & - & $\begin{array}{l}2.63 \text { TWSTRS } \\
\text { units decrease }\end{array}$ & $\begin{array}{l}3.45 \text { TWSTRS } \\
\text { units decrease }\end{array}$ & $\begin{array}{l}\text { The mean change was } \\
0.83 \text { TWSTRS units high- } \\
\text { er ( } 1.75 \text { lower to } 0.09 \\
\text { higher) in the BtB group } \\
\text { compared to the BtA } \\
\text { group }\end{array}$ & $\begin{array}{l}\oplus \oplus \ominus \ominus \\
\text { LOW 2, } 4 \\
\text { Due to study limita- } \\
\text { tions and impreci- } \\
\text { sion }\end{array}$ & $\begin{array}{l}\text { There may be little or } \\
\text { no difference in the } \\
\text { risk of cervical dysto- } \\
\text { nia-associated pain }\end{array}$ \\
\hline
\end{tabular}




\begin{tabular}{|c|c|c|c|c|c|c|}
\hline $\begin{array}{l}\text { Adverse events: sore throat/dry } \\
\text { mouth } \\
\text { № of participants: } 212 \\
\text { (2 RCTs) }\end{array}$ & $\begin{array}{l}\text { RR 4.39 } \\
\text { (2.43 to } 7.91 \text { ) }\end{array}$ & $10.5 \%$ & $\begin{array}{l}46.7 \% \\
(25.5 \text { to } 82.9)\end{array}$ & $\begin{array}{l}35.5 \% \text { more } \\
\text { (15 more to } 72.4 \text { more) }\end{array}$ & $\begin{array}{l}\oplus \oplus \oplus \ominus \\
\text { MODERATE2, } 4 \\
\text { Due to study limita- } \\
\text { tions and impreci- } \\
\text { sion }\end{array}$ & $\begin{array}{l}\text { BtB treatment prob- } \\
\text { ably increases the } \\
\text { risk of sore throat/dry } \\
\text { mouth }\end{array}$ \\
\hline $\begin{array}{l}\text { Adverse events: dysphagia } \\
\text { № of participants: } 249 \\
\text { (3 RCTs) }\end{array}$ & $\begin{array}{l}\text { RR } 2.89 \\
\text { (0.80 to } 10.41)\end{array}$ & $10.2 \%$ & $\begin{array}{l}29.4 \% \\
\text { (8.1 to } 100.0)\end{array}$ & $\begin{array}{l}19.2 \% \text { more } \\
\text { (2 fewer to } 95.6 \text { more) }\end{array}$ & $\begin{array}{l}\oplus \oplus \ominus \ominus \\
\text { LOW } \mathbf{2 , 4 , 5} \\
\text { Due to study limita- } \\
\text { tions, imprecision, } \\
\text { and inconsistency }\end{array}$ & $\begin{array}{l}\text { There may be little or } \\
\text { no difference in the } \\
\text { risk of dysphagia }\end{array}$ \\
\hline
\end{tabular}

${ }^{*}$ The risk in the intervention group (and its $95 \%$ confidence interval) is based on the assumed risk in the comparison group and the relative effect of the intervention (and its $95 \% \mathrm{Cl}$ ).

BtA: botulinum toxin type A; BtB: botulinum toxin type B; Cl: confidence interval;PGA: Patient Global Assessment; RCT: randomised controlled trial; RR: risk ratio;

TWSTRS: Toronto Western Spasmodic Torticollis Rating Scale

\section{GRADE Working Group grades of evidence}

High quality: we are very confident that the true effect lies close to that of the estimate of the effect.

Moderate quality: we are moderately confident in the effect estimate: The true effect is likely to be close to the estimate of the effect, but there is a possibility that it is substantially different.

Low quality: our confidence in the effect estimate is limited: The true effect may be substantially different from the estimate of the effect.

Very low quality: we have very little confidence in the effect estimate: The true effect is likely to be substantially different from the estimate of effect.

1 Serious imprecision: $95 \% \mathrm{Cl}$ includes both appreciable benefit and no effect. This means that we cannot conclusively state the equivalence of these two formulations.

2 Serious study limitations: the limitations in the studies assessing this outcome are serious and affect our confidence in the accuracy of the effect estimate.

3 Very serious imprecision: the total number of participants included was less than the number generated by a conventional sample size calculation for a single adequately powered equivalence trial. $95 \% \mathrm{Cl}$ includes both appreciable benefit and harm meaning that we cannot conclusively state the equivalence of these two formulations.

4 Serious imprecision: the total number of participants included was less than the number generated by a conventional sample size calculation for a single adequately powered equivalence trial.

5 Serious inconsistency: high degree of heterogeneity expressed by $\mathrm{I}^{2}$ and low overlap of $95 \% \mathrm{CI}$. 


\section{B A C K G R O U N D}

This review is an update of a previously published review in the Cochrane Database of Systematic Reviews 2003, Issue 3 (Costa 2003), evaluating the efficacy and safety of botulinum toxin type $A(B t A)$ versus botulinum toxin type $B(B t B)$ in the treatment of cervical dystonia.

\section{Description of the condition}

See Table 1 for glossary of terms.

Dystonia is the third most common movement disorder, after Parkinson's disease and essential tremor, with an overall prevalence of 164 per million (Steeves 2012). Dystonia syndromes are a group of disabling, painful disorders characterised by involuntary sustained or intermittent muscle contractions that cause abnormal, often repetitive, movements or postures of the face, neck, trunk or limbs (Albanese 2013). Dystonic movements are typically patterned or twisting, and are often initiated or worsened by voluntary action (Albanese 2013). These neurological disorders can be classified on the basis of topographic distribution, including focal dystonia (one body region, e.g. cervical dystonia (involuntary movements of head and neck) and blepharospasm (involuntary closure of the eyes)), segmental dystonia (two or more adjacent regions), multifocal dystonia (two or more nonadjacent regions), hemidystonia (ipsilateral regions (same side of the body)) and generalised dystonia (trunk and two or more other regions) (Albanese 2013; Tarsy 2006).

Focal dystonia is a highly disabling movement disorder, with serious functional and social impairment. Close to half of the dystonia patient population quits work by the age of forty or retires early due to the condition, and 10 years later, only $25 \%$ of people are working compared to $62 \%$ of the general population (Zoons 2012). Moreover, health-related quality of life is significantly diminished, mainly due to depression and anxiety, with scores comparable to people with multiple sclerosis, Parkinson's disease or stroke (Zoons 2012).

Cervical dystonia, also called spasmodic torticollis, is the most common form of adult-onset focal dystonia, with estimates from population studies ranging from 57 per million in Europe (ESDE 2000), to as high as 280 per million in the USA (Jankovic 2006). Typically, its onset occurs in the fifth decade of life (Albanese 2013), and it affects more women than men (Defazio 2013). This condition is characterised by abnormal movements of head, neck, and shoulder, resulting in posturing of the head away from its normal central position (Foltz 1959). It may present predominantly with sustained abnormal posture, spasm, jerks, tremor, or a combination of these features. Neck or shoulder pain, or both, occur in more than $70 \%$ of individuals with cervical dystonia (Chan 1991; Tarsy 2006).

Cervical dystonia can be classified according to the dominant head position, with the most common type involving horizontal turning, the so-called rotatory (or simple) torticollis (Albanese 2013; Chan 1991). Other common patterns include laterocollis (tilt to one side), retrocollis (tilt upwards resulting in neck extension) and anterocollis (tilt downwards resulting in neck flexion). Complex torticollis is a combination of these abnormal patterns, and is found relatively infrequently in clinical practice.
The aetiology of most forms of dystonia is still not fully understood, with the exception of early-onset dystonia, for which a hereditary aetiology is common (Balint 2015). In most cases of focal adultonset dystonia, such as cervical dystonia, the pathophysiology is generally considered to result from inhibition of the central nervous system (CNS) at multiple levels (Hallett 1998), resulting in abnormal sensorimotor integration. Cervical dystonia can also be secondary to brain injury, infections of the CNS, drugs (such as levodopa or antipsychotics), toxins, vascular or neoplastic disorders, and may also be psychogenic (i.e. have a psychological origin) (Albanese 2013). Although most cases of cervical dystonia are currently classified as idiopathic (of unknown cause), it should be observed that some may come to be reclassified as inherited, since new gene discoveries are under investigation (Albanese 2013; Balint 2015).

The natural course of cervical dystonia remains unclear. It usually develops gradually and worsens over the initial years. The clinical presentation in adults seldom progresses to generalised dystonia, although it often extends to contiguous body regions. For most individuals, cervical dystonia is a life-long disorder, with only about $10 \%$ undergoing spontaneous remissions (Jahanshani 1990).

To date, no curative or disease-modifying treatments are available for cervical dystonia.

\section{Description of the intervention}

Botulinum toxin (Bt) is a powerful biological toxin produced by the bacterium Clostridium botulinum. The active form of botulinum toxin is a polypeptide composed of two chains: a heavy chain $(100 \mathrm{kDa})$ and a light chain $(50 \mathrm{kDa})$, and by associating with certain auxiliary proteins (haemagglutinins and non-haemagglutinins), the toxin forms a complex of variable size (Simpson 2004). The nontoxic proteins aid the formation of neutralising antibodies, though beyond this their role is unclear (Frevert 2010). Bt binds to peripheral cholinergic nerve terminals of the neuromuscular junction as well as sympathetic, parasympathetic and postganglionic terminals (Simpson 2004). $\mathrm{Bt}$, after binding to an acceptor protein, is endocytosed at the presynaptic membrane of acetylcholine nerve terminals (Pellizzari 1999). Through the action of the N-terminal on the heavy-chain, a pore is formed on the endocytic membrane, which permits the release of the light-chain into the cytosol. This light chain, which is a zinc protease, performs the key action of botulinum toxin, by cleaving soluble $\mathrm{N}$-ethylmaleimide sensitive factor attachment receptor proteins (SNARE proteins) (Pellizzari 1999).

SNAREs are docking proteins for acetylcholine vesicles that allow for the release of acetylcholine into the synaptic cleft (Pellizzari 1999). As the fusion of the vesicle membranes becomes inhibited, there is a temporary blockade of acetylcholine release at cholinergic synapses, causing a local chemodenervation. Temporary synapses are consequently formed via the process of axonal sprouting (Duchen 1971; Holland 1981; Juzans 1996).

There are seven immunologically distinct botulinum toxin serotypes (labelled A to $G$ ). These different Bt serotypes cleave specific SNARE proteins. Serotype A cleaves SNARE protein SNAP 25 located on the inner membrane, and serotype B targets synaptobrevin located on the vesicular membrane (Pellizzari 1999).

Botulinum toxin is injected into the muscles involved in dystonia, with or without guidance by either electromyography (EMG) or 
ultrasound. As a general rule, the overall dose, the number of muscles injected and the number of injection sites per muscle are tailored to the severity of the case and the mass of the muscle. Within roughly three months after injection of botulinum toxin into skeletal muscle, the nerve terminal resumes exocytosis, and the muscle returns to its baseline clinical function, showing a wearing off of response from the Bt injection (Jankovic 2004). Eventually, the muscle paralysis subsides, and this is associated with the formation of new nerve sprouts capable of neurotransmission. Over time, synaptic activity resumes in the original nerve terminals, leading to sprout regression (de Paiva 1999).

Currently there are two commercially available botulinum toxin serotypes (BtA and $B t B)$. The following products are commonly available (three $B t A$ and one $B t B$ ): onabotulinumtoxinA (Botox, Allergan Inc, Irvine, CA, USA), abobotulinumtoxinA (Dysport/ Reloxin/Azzalure, Ipsen Pharma, Boulogne Billancourt, France), incobotulinumtoxinA (Xeomin/Bocoture Merz GmbH, Frankfurt, Germany), and rimabotulinumtoxin B (Myobloc/Neurobloc, Solstice Neurosciences Inc, Louisville, KY, USA). Other BtA formulations are available in more restricted markets and are yet to receive a generic name: Prosigne/Lantox (Lanzhou Institute of Biological Products, China), PurTox (Mentor Worldwide LLC, Santa Barbara, CA, USA), and Neuronox (Medy-Tox Inc, South Korea) (Walker 2014). Each type of Bt has its own relative potency and it is estimated that $1 \mathrm{U}$ of onabotulinumtoxinA roughly corresponds to $1 \mathrm{U}$ of incobotulinumtoxin $\mathrm{A}, 3 \mathrm{U}$ to $5 \mathrm{U}$ of abobotulinumtoxinA, and 50 $\mathrm{U}$ of rimabotulinumtoxinB (Bentivoglio 2015). The treatment cost per patient for each of the formulations is highly variable, and depends greatly on the country and individual characteristics of the people being treated, including responsiveness to Bt and number of muscles affected. Having in mind the 2016 prices per vial for each of the formulations currently available in the UK, and their relative potencies, $200 \mathrm{U}$ of onabotulinumtoxinA cost GBP 276, $200 \mathrm{U}$ of incobotulinumtoxinA cost GBP 260, $600 \mathrm{U}$ to $1000 \mathrm{U}$ of abobotulinumtoxinA cost GBP 184 to GBP 308, and 10,000 U of rimabotulinumtoxinB cost GBP 198 (BNF 2016a; BNF 2016b).

\section{How the intervention might work}

The therapeutic potential of all Bt serotypes derives from their ability to inhibit the release of acetylcholine from the presynaptic nerve terminal into the synaptic cleft, causing local chemodenervation (Jankovic 2004). In addition to this, recent research has also suggested that Bt is active at multiple levels, namely sensory nerve terminals, and muscle spindles, which leads to a reduction in sensory input and fewer muscle contractions (Filippi 1993; Matak 2014; Rosales 1996; Rosales 2010).

It has also been suggested that cortical reorganisation may result from changes in the spinal cord, brainstem and central nervous pathways (Palomar 2012). Animal research has shown the presence of supra-therapeutic levels of Bt by way of retrograde axonal transport and penetration of the central nervous system (Antonucci 2008; Boroff 1975). However, Bt has not been shown to penetrate the blood-brain barrier in humans.

Until recently, SNARE proteins were considered to be the only target-molecules of Bt. Thus, it was widely accepted that the therapeutic and toxic actions of Bt were exclusively mediated by SNARE cleavage preventing the release of synaptic neurotransmitters. However, recent studies have suggested that a number of Bt actions might not be mediated by SNARE cleavage, specifically regarding neuroexocytosis, cell cycle (division) and apoptosis (programmed cell death), neuritogenesis (formation of nerves) and gene expression (Matak 2015). The existence of unknown Bt molecular targets and modulation of unknown signalling pathways is a possibility that may prove to be relevant pharmacologically.

\section{Why it is important to do this review}

BtA is the toxin serotype that has been most intensively studied and approved for the treatment of a large number of focal dystonias. BtA is considered the first line therapy for cervical dystonia (Albanese 2013). However, not all people with cervical dystonia have an adequate clinical response. Primary non-response to $B t$ is seen in cases where the first and subsequent treatment cycles do not elicit a response. Cases of secondary non-response, however, respond to initial treatment, but over the course of multiple treatment cycles, this effect wanes and is eventually lost. Secondary non-responsiveness is partially explained by the formation of neutralising antibodies, though it is worth noting that there are cases of secondary non-responders without positive antibody titers (Hanna 1998; Lange 2009), as well as cases with positive titers with a maintained clinical response to Bt (Brin 2008; Müller 2009). An estimated $4 \%$ to $20 \%$ of people with cervical dystonia develop neutralising antibodies to the toxin (Brashear 2008; Fabbri 2015), and if secondary non-responsiveness occurs, it is partially related to the protein load, with a higher protein load per dose generating higher antibody titers (Benecke 2012; Frevert 2010).

At the present time, BtB is the only approved non-BtA formulation available for the treatment of cervical dystonia in the European Union and North America. Both BtA and BtB have been shown to be efficacious in comparison to placebo in the treatment of adults with cervical dystonia (Costa 2005; Marques 2016), although with apparently different safety profiles. In the context of cervical dystonia, BtB is of particular interest as a treatment option for individuals who are non-responsive to BtA (Cullis 2000; Eleopra 1997; Greene 1993).

Although different Bt subtypes have different molecular targets, to date we know of no evidence from systematic reviews or randomised controlled trials that presents conclusive evidence regarding the comparative effectiveness of $\mathrm{Bt} A$ and $\mathrm{Bt} B$ for treating cervical dystonia.

This is an update of a Cochrane systematic review that previously assessed this question. The original review failed to included any trials addressing clinical comparability of BtA versus BtB in cervical dystonia. Since the release of the original review, three trials have been published (Comella 2005; Pappert 2008; Tintner 2005). Furthermore, Cochrane's criteria for evaluating studies' risk of bias and quality of evidence have evolved and been updated. Therefore, the authors consider it important to update this review.

\section{O B JECT IVES}

To compare the efficacy, safety and tolerability of botulinum toxin type $A$ versus botulinum toxin type $B$ in people with cervical dystonia. 


\section{METHODS}

\section{Criteria for considering studies for this review}

\section{Types of studies}

Randomised controlled trials (RCTs), blinded, single or multiple dose, parallel-designed, of any duration, assessing the efficacy or safety, or both, of treatment with BtA versus BtB in adults with cervical dystonia were eligible for inclusion in this review. If trials had used inadequate randomisation or allocation concealment methods we would have included these only in the safety analyses. Non-parallel study designs, namely cross-over trials, were excluded in this updated version of the review, due to uncertainty about whether this type of study design was appropriate for studying people with cervical dystonia, as well as methodological concerns with regard to detection and performance bias.

\section{Types of participants}

Adults (i.e. 18 years of age and over), in any setting, with a clinical diagnosis, made by any physician, specialist or otherwise, of idiopathic cervical dystonia. We included trials that enrolled participants with any form of cervical dystonia, and additional or more widespread dystonias. Participants could have prior exposure to $\mathrm{BtA}$ or BtB, and could be taking any concomitant medications, if on stable regimens.

There were no restrictions regarding the number of participants recruited to trials, or the number of recruitment centres.

\section{Types of interventions}

Intramuscular injections of BtA compared to BtB. We allowed all administration schedules and injection techniques, performed with or without guidance by either EMG or ultrasound.

\section{Types of outcome measures}

\section{Primary outcomes}

\section{Primary efficacy outcome}

Overall improvement on any validated symptomatic rating scale, such as Tsui scale, Toronto Western Spasmodic Torticollis Rating Scale (TWSTRS), and Cervical Dystonia Severity Scale (CDSS), measured between weeks 3 and 6 post-injection.

\section{Primary safety outcome}

Proportion of participants with any adverse event, measured at any point during study follow-up.

\section{Secondary outcomes}

- Change in subjective evaluation of clinical status evaluated by both patients and clinicians, as assessed with validated assessment tools such as the Patient Subjective Assessment of Change, Patient Global Assessment of Improvement, Patient Evaluation of Global Response (PEGR), Patient and Physician Global Assessment of Change, Investigator Global Assessment of Efficacy (IGAE), Physician Global Assessment of Change (PGAC), and visual analogue scale (VAS) for symptom severity, measured between weeks 3 and 6 post-injection.

- Changes in pain scores, as assessed with validated assessment tools such as the Patient Assessment of Pain, TWSTRS-pain sub- scale score, and VAS Pain score, measured between weeks 2 and 6 post-injection.

- Changes in quality of life assessments, as assessed with validated assessment tools such as the Short Form 36 (SF-36) quality-of-life questionnaire, measured at any point during study follow-up.

- Numbers of participants with adverse events of special interest, such as dysphagia, sore throat, and local injection-site pain, measured at any point during study follow-up.

- Duration of effect, assessed by the number of days until need for reinjection or effect waning.

\section{Search methods for identification of studies}

For this update, we expanded the search strategy to capture all the search terms for BtA and BtB formulations that were available at the time of the search. We designed the search strategy to include other botulinum toxin formulations and other dystonic disorders that were also under revision by our group.

\section{Electronic searches}

We ran the final search for the original version of this review in June 2003, based on the search strategy developed for the Movement Disorders Group to identify all papers from 1977, the first year botulinum toxin was used therapeutically in any condition. The search for the current update was run for the last time in October 2016.

For the identification of studies considered for inclusion in this review, we developed detailed search strategies for each database searched. Please see Appendix 1 for the CENTRAL strategy, Appendix 2 for the MEDLINE search strategy, and Appendix 3 for the EMBASE strategy.

We assessed non-English language papers, translated them as necessary and evaluated them for inclusion.

We did not search trial registries.

\section{Databases searched}

- Cochrane Movement Disorders Group trials register (June 2003);

- Cochrane Central Register of Controlled Trials (CENTRAL; the Cochrane Library 2016, Issue 11);

- MEDLINE (1977 to 6 October 2016);

- Embase (1977 to 6 October 2016).

\section{Searching other resources}

The search strategy also included:

- searches through reference lists of located trials and review articles concerning botulinum toxin;

- handsearch of abstracts of international congresses relevant in the fields of movement disorders and botulinum toxins, i.e. American Academy of Neurology, Movement Disorders Society, International Association of Parkinsonism and Related Disorders, and International Neurotoxin Association (1985 to October 2016);

- personal communication with other researchers in the field;

- contact with drug manufacturers; 
- whenever necessary, we contacted authors of published trials for further information and unpublished data.

\section{Data collection and analysis}

\section{Selection of studies}

Two authors independently screened all titles and abstracts identified from searches to determine which met the inclusion criteria. We retrieved in full text any papers identified as potentially relevant by at least one author, or those without an available abstract. Two review authors independently screened full text articles, with discrepancies resolved by discussion and by consulting a third author where necessary to reach consensus. We collated duplicate publications and present these by individual study. The screening and selection process is outlined in a PRISMA flow chart (Liberati 2009), see Figure 1. 
Figure 1. BtA vs BtB in Cervical Dystonia Flow Diagram.

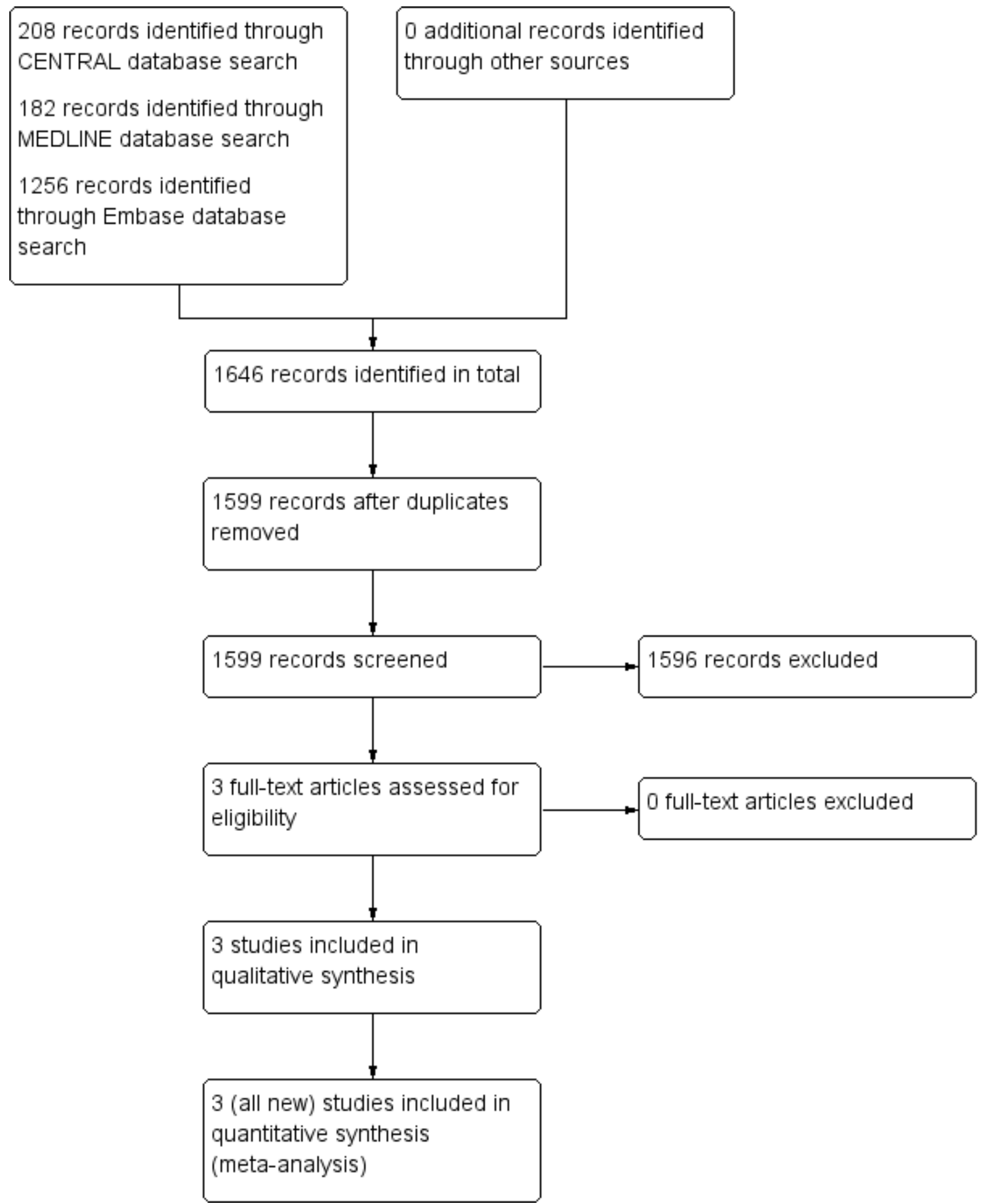

\section{Data extraction and management}

Two review authors extracted data independently from included studies using a piloted data extraction form. Any discrepancies were resolved by discussion until consensus was reached, or through consultation with a third author where necessary. The authors extracted data on the following items from each study. 
- Participants: inclusion and exclusion criteria, demographics and clinical baseline characteristics, number and reasons for withdrawals, exclusions and loss to follow-up, if any.

- Interventions: full description of intervention, duration of treatment period and follow-up, providers, and cointerventions, if any.

- Comparisons: number of participants randomised to each arm, compliance and dropouts, reasons for dropouts, and ability to perform an intention-to-treat analysis.

- Outcomes: definition of outcomes, use of validated measurement tools, time point measurements, change from baseline or post-interventional measures, and missing outcomes, if any.

- Study design: interventional, randomised, controlled, doubleblind.

\section{Assessment of risk of bias in included studies}

We assessed the risk of bias of included studies according to the domains described in the Cochrane tool for assessing risk of bias (Higgins 2011b), and classified the risk of bias for each domain as high, unclear, or low, and the overall assessment as high or low. We assessed two further domains, which are described below: 'for-profit bias' and 'enriched population'. We used the following definitions for each domain in the 'Risk of bias' assessment.

\section{Random sequence generation}

- Low risk of bias: the study performed sequence generation using computer random number generation or a random number table. Drawing lots, tossing a coin, shuffling cards, and throwing dice were adequate if an independent person not otherwise involved in the study performed them.

- Unclear risk of bias: the study authors did not report the sequence generation method.

- High risk of bias: the sequence generation method was not random.

\section{Allocation concealment}

- Low risk of bias: participants and investigators enrolling participants could not foresee assignment because one of the following, or an equivalent method, was used to conceal allocation: central allocation, sequentially numbered drug containers of identical appearance; sequentially numbered, opaque, sealed envelopes.

- Unclear risk of bias: insufficient information available to permit a judgement of 'low risk' or 'high risk'.

- High risk of bias: participants or investigators enrolling participants could possibly foresee assignments and thus introduce selection bias.

In addition to these criteria, we considered the implications of baseline imbalances in prognostic factors affecting the trial outcomes, as these may lead to selection bias (Corbett 2014).

\section{Blinding of participants and personnel}

- Low risk of bias: either of the following: no blinding or incomplete blinding, but the review authors judge that the outcome is not likely to be influenced by lack of blinding; or blinding of participants and key study personnel ensured, and it is unlikely that the blinding could have been broken.
- Unclear risk of bias: any of the following: insufficient information available to permit a judgement of 'low risk' or 'high risk'; or the trial did not address this outcome.

- High risk of bias: either of the following: no blinding or incomplete blinding, and the outcome is likely to be influenced by lack of blinding; or blinding of key study participants and personnel attempted, but likely that the blinding could have been broken, and the outcome is likely to be influenced by lack of blinding.

\section{Blinded outcome assessment}

We considered blinding separately for different outcomes, as appropriate, and, to aid in the process, divided the domain into two categories: subjective and objective assessment.

- Low risk of bias: either of the following: no blinding of outcome assessment, but the review authors judge that the outcome measurement is not likely to be influenced by lack of blinding; or blinding of outcome assessment ensured, and it is unlikely that the blinding could have been broken.

- Unclear risk of bias: any of the following: insufficient information available to permit a judgement of 'low risk' or 'high risk'; or the trial did not address this outcome.

- High risk of bias: either of the following: no blinding of outcome assessment, and the outcome measurement is likely to be influenced by lack of blinding; or blinding of outcome assessment, but likely that the blinding could have been broken, and the outcome measurement is likely to be influenced by lack of blinding.

\section{Incomplete outcome data}

- Low risk of bias: missing data were unlikely to make treatment effects depart from plausible values. The study used sufficient methods, such as multiple imputation, to handle missing data.

- Unclear risk of bias: there was insufficient information available to assess whether missing data in combination with the method used to handle missing data were likely to induce bias to the results.

- High risk of bias: the results were likely to be biased due to missing data.

\section{Selective outcome reporting}

- Low risk: the trial reported the following predefined outcomes: if the original trial protocol was available, the outcomes reported by the trial were listed in that protocol; if the trial protocol was obtained from a trial registry, the outcomes reported by the trial should have been those enumerated in the original protocol if the trial protocol was registered before or at the time that the trial was begun.

- Unclear risk: the study authors did not report all predefined outcomes fully, or it is unclear whether the study authors recorded data on outcomes or not.

- High risk: the study authors did not report one or more predefined outcomes; if the trial protocol was registered after the trial was begun, we did not consider those outcomes to be reliable. 


\section{For-profit bias}

In order to assess the study source of funding, this domain was added in place of the 'other bias' domain.

- Low risk of bias: the trial appears to be free of industry sponsorship or other type of for-profit support that may manipulate the trial design, conductance, or reporting of trial results.

- Unclear risk of bias: the trial may or may not be free of for-profit bias as the trial does not provide any information about clinical trial support or sponsorship.

- High risk of bias: the trial is sponsored by industry or received other type of for-profit support.

\section{Enriched population}

Because the clinical effect of botulinum toxin treatment is easily perceived, Bt non-naive participants are likely to recognise the presence or absence of clinical effects, or frequent adverse events, or both, effectively revealing the respective allocation arm. It is also relevant that, by preferentially including responders to $\mathrm{Bt}$ or excluding non-responders to $\mathrm{Bt}$, there is an increased likelihood that these participants respond more favourably to $\mathrm{Bt}$ than a naive population would. We opted to subdivide this domain in two: preferential enrolment of known positive responders to Bt; and exclusion of known poor responders to $\mathrm{Bt}$.

- Low risk of bias: at least $70 \%$ of trial participants were Bt-naive; the trial did not exclude any particular forms of cervical dystonia.

- Unclear risk of bias: the trial did not make explicit the percentage of participants who were known responders to Bt.

- High risk of bias: arbitrarily defined as more than $30 \%$ of participants non-naive to Bt; explicit exclusion of people with forms of cervical dystonia known to have a poor response to Bt, namely people with pure anterocollis and retrocollis.

\section{Measures of treatment effect}

We compared disease symptoms at baseline to disease symptoms in weeks 2 to 4 post-injection in the BtA and BtB arms. We extracted continuous outcomes whenever possible. These data were then pooled from the studies, where adequate, and used for comparison.

\section{Dichotomous data}

We based analysis of these data on the number of events and the number of people assessed in the intervention and comparison groups. We used these to calculate the risk ratio (RR) and 95\% confidence interval $(\mathrm{Cl})$.

\section{Continuous data}

We based analysis of these data on the mean, standard deviation (SD) and number of people assessed for both the intervention and comparison groups to calculate mean difference (MD) and $95 \% \mathrm{Cl}$. Where the MD was reported without individual group data, we used this to report the study results. If more than one study measured the same outcome using different validated tools, we calculated the standardised mean difference (SMD), namely Hedges' (adjusted) $g$ (Hedges 1985), and 95\% Cl. For interpretation of effect sizes with SMDs, we used a rule of thumb to define a small effect (SMD = $0.2)$, a moderate effect (SMD $=0.5)$, or a large effect $(S M D=0.8)$ (Cohen 1988). If necessary for comparison, we dichotomised rating scales using each study author's own criteria for improvement or no improvement.

\section{Time-to-event data}

We planned to analyse these data based on log hazard ratios and standard errors obtained from results of Cox proportional hazards regression models. We had planned to use these in order to calculate a hazard ratio $(\mathrm{HR})$ and $95 \% \mathrm{Cl}$.

\section{Unit of analysis issues}

Whenever the included studies had multiple arms with different dosages of one or two of the botulinum toxins, we combined all groups to create a single pair-wise comparison, using the Review Manager 5 (RevMan 5) calculator (RevMan 2014), according to the methods suggested by Cochrane (Higgins 2011c). We also would have opted to create a single pair-wise comparison in case of multiple treatment groups using different interventions (e.g. onabotulinumtoxinA and abobotulinumtoxinA) if these were compared to the same comparator.

This method combines all relevant experimental intervention groups of the study into a single group, and combines all relevant control intervention groups into a single control group. This approach avoided the duplication of the control group that would happen if multiple comparisons (e.g. BtX dose1 versus BtY; BtX dose 2 versus $B t Y$ ) were included in the meta-analysis, as well as the loss of information if one dosage group was chosen to the detriment of the others. If applicable, we planned to explore the effect of dosage in subgroup analysis.

For dichotomous outcomes, both the sample sizes and the numbers of people with events would have been summed across groups. For continuous outcomes, means and standard deviations could be combined using a pooled mean or SD (Higgins 2011a; Higgins 2011c).

\section{Dealing with missing data}

For missing outcome or summary data we used imputation methods to derive the missing data (where possible) and reported any assumptions in the review. These cases were investigated, through sensitivity analyses, to investigate the effects of any imputed data on pooled effect estimates.

As a first option we chose to use the available information (e.g. standard error (SE), $95 \% \mathrm{Cl}$ or exact $\mathrm{P}$ value) to recover the missing data algebraically (Higgins 2011a; Higgins 2011c; Wiebe 2006). When change from baseline SD was not reported or not possible to extract, as was the case in Tintner 2005, we attempted to create a correlation coefficient based on another study in this review, and then used this correlation coefficient to impute a change from baseline SD (Abrams 2005; Follmann 1992; Higgins 2011c).

If this were to fail, and if at least one sufficiently large and similar study were to exist, we would use a method of single imputation (Furukawa 2006; Higgins 2011c).

Lastly, if a sufficient number of included studies with complete information were to exist, we would have used multiple imputation methods to derive missing data (Carpenter 2013; Rubin 1991).

If none of these methods were to be successful we would have conducted a narrative synthesis for the data in question. 


\section{Assessment of heterogeneity}

We assessed that studies were similar enough to allow pooling of data using meta-analysis. Where data was pooled using metaanalysis, we assessed the degree of heterogeneity by visual inspection of forest plots and by examining the $\mathrm{Chi}^{2}$ test for heterogeneity. We quantified heterogeneity using the $1^{2}$ statistic. We considered an 12 value of $50 \%$ or more to represent substantial levels of heterogeneity, but interpreted this value in light of the size and direction of effects and the strength of the evidence for heterogeneity, based on the $\mathrm{P}$ value from the $\mathrm{Chi}^{2}$ test (Higgins 2003).

\section{Assessment of reporting biases}

We included too few studies in this review, namely fewer than 10 , to allow construction of a funnel plot (Sterne 2001), and formal testing of asymmetry (Peters 2006), which may indicate publication bias. Should enough studies be included in future updates of this review, we plan to undertake these analyses.

\section{Data synthesis}

We performed the analyses with RevMan 5 version 5.3 (RevMan 2014), Stata version 14 (Stata 2015) and TSA (Thorlund 2011; TSA 2011).

\section{Meta-analysis}

We based the decision whether or not to meta-analyse data on an assessment of whether the interventions in the included trials were similar enough in terms of participants, settings, intervention, comparison and outcome measures to ensure meaningful conclusions from a statistically pooled result. We conducted data synthesis using a random-effects model.

We pooled effect measures by applying the Mantel-Haenszel method for dichotomous outcomes, and applying the inversevariance or generic inverse-variance method for continuous outcomes. In addition, we had planned to pool time-to-event data using the generic inverse-variance method. We presented all results with $95 \% \mathrm{Cl}$.

We calculated the number of participants needed to treat for an additional beneficial outcome (NNTB) and for an additional harmful outcome (NNTH) from meta-analysis estimates, rather than treating data as if they came from a single trial, as the latter approach is more prone to bias, especially when there are significant imbalances between groups within one or more trials in the meta-analysis (Altman 2002). However, caution is needed in the interpretation of these findings since they may be misleading because of variation in the event rates in each trial, differences in the outcomes considered, and differences in clinical setting (Smeeth 1999).

Where there were no data that could be combined into a metaanalysis we undertook a narrative approach to result synthesis.

\section{Trial sequential analysis}

In order to explore whether the cumulative data were of adequate power to evaluate the primary outcomes of this review, we performed a trial sequential analysis (Wetterslev 2008), and calculated a required information size (also known as the heterogeneity-adjusted required information size) (Wetterslev 2009).
Trial sequential analysis aims to evaluate whether statistically significant results of meta-analysis are reliable by accounting for the required information size (i.e. the number of participants in the meta-analysis required to accept or reject an intervention effect). The technique is analogous to sequential monitoring boundaries in single trials. Trial sequential analysis adjusts the threshold of statistical significance and has been shown to reduce the risk of random errors due to repetitive testing of accumulating data (Imberger 2016).

We calculated the required information size and computed the trial sequential monitoring boundaries using the O'Brien-Fleming approach (O'Brien 1979). The required information size was based on the event proportion or standard deviation in the control group; assumption of a plausible relative risk reduction (RRR) of $10 \%$; a $5 \%$ risk of type I error; a $20 \%$ risk of type II error (power $=80 \%$ ); and the observed heterogeneity of the meta-analysis (Jakobsen 2014; Wetterslev 2009).

\section{Assessing the quality of the evidence}

As recommended by the Grading of Recommendations Assessment, Development and Evaluation (GRADE) Working Group methodology (Schünemann 2011), two reviewers independently assessed all of the outcomes in the following domains: study limitations, inconsistency, indirectness, imprecision and publication bias. In case of disagreement the authors attempted to reach consensus, consulting an independent third reviewer if necessary. For this purpose, we used the GRADEprofiler (GRADEpro GDT) software tool (GRADEpro GDT 2014), which we then used to export a 'Summary of findings' table for inclusion in the review manuscript.

To ensure the consistency and reproducibility of GRADE judgements, we applied the following criteria to each domain for all key comparisons of the critical outcomes.

- Study limitations: we downgraded once if more than $30 \%$ of participants were from studies classified as being at a high risk of bias across any domain, with the exception of 'for-profit bias'.

- Inconsistency: we downgraded once if heterogeneity was statistically significant or if the $\mathrm{I}^{2}$ value was more than $40 \%$. When a meta-analysis was not performed we downgraded once if trials did not show effects in the same direction.

- Indirectness: we downgraded once if more than $50 \%$ of the participants were outside the target group.

- Imprecision: we downgraded once if the optimal information size criterion was not met or, alternatively, if it was met but the $95 \% \mathrm{Cl}$ fails to exclude important benefit or important harm (Guyatt 2011).

- Publication bias: we downgraded once where there was direct evidence of publication bias or if estimates of effect based on small scale, industry-sponsored studies raised a high index of suspicion of publication bias.

We applied the following definitions to the quality of evidence (Balshem 2011):

- high quality: we are very confident that the true effect lies close to that of the estimate of the effect; 
- moderate quality: we are moderately confident in the effect estimate; the true effect is likely to be close to the estimate of the effect, but there is a possibility that it is substantially different;

- low quality: our confidence in the effect estimate is limited; the true effect may be substantially different from the estimate of the effect;

- very low quality: we have very little confidence in the effect estimate; the true effect is likely to be substantially different from the estimate of effect.

\section{'Summary of findings' table}

As has become standard practice in Cochrane Reviews, we have included a 'Summary of findings' table to present the main findings of this review in a simple tabular format, based on the results of the GRADE analysis. In particular, we included key information concerning the quality of evidence, the magnitude of effect of the interventions examined, and the sum of available data on the outcome overall cervical dystonia improvement, proportion of participants with adverse events, subjective change as assessed by the patient, cervical dystonia associated pain, sore throat/dry mouth, and dysphagia (difficulty swallowing).

\section{Subgroup analysis and investigation of heterogeneity}

We planned to conduct subgroup analyses according to the dosages of Bt used, though this was not possible given the paucity of results. In particular, we included key information concerning the quality of evidence, the magnitude of effect of the interventions examined, and the sum of the available data on the outcome.

\section{RES U L T S}

\section{Description of studies}

We identified three new studies for inclusion in this update: Comella 2005; Pappert 2008; Tintner 2005.

\section{Results of the search}

See: Figure 1, flow diagram of study selection.

We last ran the electronic search in October 2016. The search returned 1646 records (208 through CENTRAL; 182 though MEDLINE; 1256 through Embase), resulting in 1599 records after removing all duplicates. After title and abstract screening, three articles were assessed for full-text screening, with all three being included for both the qualitative and quantitative syntheses. We did not retrieve any unpublished trials.

\section{Included studies}

We have listed all the included studies in this review in the 'Characteristics of included studies' table.

The three studies included in this review are parallel-group RCTs comparing BtA and BtB for adults (i.e. 18 years of age or over) with cervical dystonia. Trial size varied from 20 to 139 participants. Two of the included RCTs were multi-centre studies conducted in North America and Europe (Comella 2005; Pappert 2008), while the remaining trial was a single-centred study conducted in the USA (Tintner 2005). All trials were conducted in the 2000s.

Overall, 270 participants were enrolled, 171 of whom were female (63.3\%). A total of 141 participants included in this review were randomised to the BtA arm of their respective studies, with the remaining 129 participants randomised to the BtB arm. The average age of participants among the three trials was 53.3 years. The baseline mean cervical dystonia symptoms were moderate to severe in all participants, and well matched between study arms, with baseline TWSTRS total scores of 41.8 and 45.6 for participants in Comella 2005 and Pappert 2008, respectively, which may be interpreted as representing a moderate overall disease impairment. Tintner 2005 did not provide data for baseline TWSTRS total score. The mean duration of cervical dystonia was 7.9 years and 6.6 years for participants in Comella 2005 and Pappert 2008, respectively. Tintner 2005 did not provide data for the number of years since diagnosis of dystonia. Pappert 2008 enrolled exclusively Bt-naive participants (no prior exposure to any form of Bt), while the remaining studies enrolled participants with a known positive response to BtA exclusively (Comella 2005; Tintner 2005). Overall, $58.9 \%$ of the participants included in this review had a known positive response to BtA. None of the included trials described the method of participant referral and recruitment prior to study enrolment. Within each study, as well as when considered together, participants were well matched for clinical and demographic characteristics between $\mathrm{Bt} A$ and $\mathrm{Bt} B$ arms at baseline.

All studies were designed to evaluate only a single treatment session. Two studies used doses from $100 \mathrm{U}$ to $250 \mathrm{U}$ of BtA both onabotulinumtoxinA formulations - and $5000 \mathrm{U}$ to $10,000 \mathrm{U}$ of BtB (Comella 2005; Pappert 2008), while the remaining study referred only to botulinum doses being administered at a 1:50 ratio of BtA (onabotulinumtoxinA formulation) to BtB (Tintner 2005). In all studies, and within these limits, the Bt doses administered were left at the discretion of the clinician. Techniques and schema of Bt administration did not vary a great deal among studies. In all trials, the toxin was injected into the muscles involved in cervical dystonia selected by the investigator, with the use of electromyography left to the discretion of the clinician performing the injection.

Comella 2005 and Pappert 2008 both used TWSTRS total score at week 4 post-injection as the primary efficacy outcome. Tintner 2005 was designed with the specific objective of comparing the autonomic effects of Bt, reporting only TWSTRS sub-scores at baseline and at week 3 post-injection. Comella 2005 and Pappert 2008 also studied subjective response as assessed by participants and clinicians. Regarding safety outcomes, all studies reported treatment-associated adverse events. Comella 2005 reported data using an intention-to-treat (ITT) principle. One study specified the method of data analysis used (Pappert 2008), stating that data was analysed using both per-protocol (PP) and ITT principles. However, only PP data were reported, with the claim by the authors that no difference existed between PP and ITT results. None of the included trials had an available protocol register.

All trials were short-term, with a follow-up period lasting 16 to 20 weeks post-injection or until such time as reinjection was required.

\section{Excluded studies}

All reports that were entered for full-text screening were assessed as eligible for inclusion in this review.

\section{Risk of bias in included studies}

See Characteristics of included studies: 'Risk of bias' table. 
The included studies were evaluated using a modified version of the Cochrane 'Risk of bias' tool. See Figure 2 and Figure 3 for the
'Risk of bias' summary graphs. These assessments were based on the information available in the primary report data.

\section{Figure 2. Risk of bias graph: review authors' judgements about each risk of bias item presented as percentages} across all included studies.

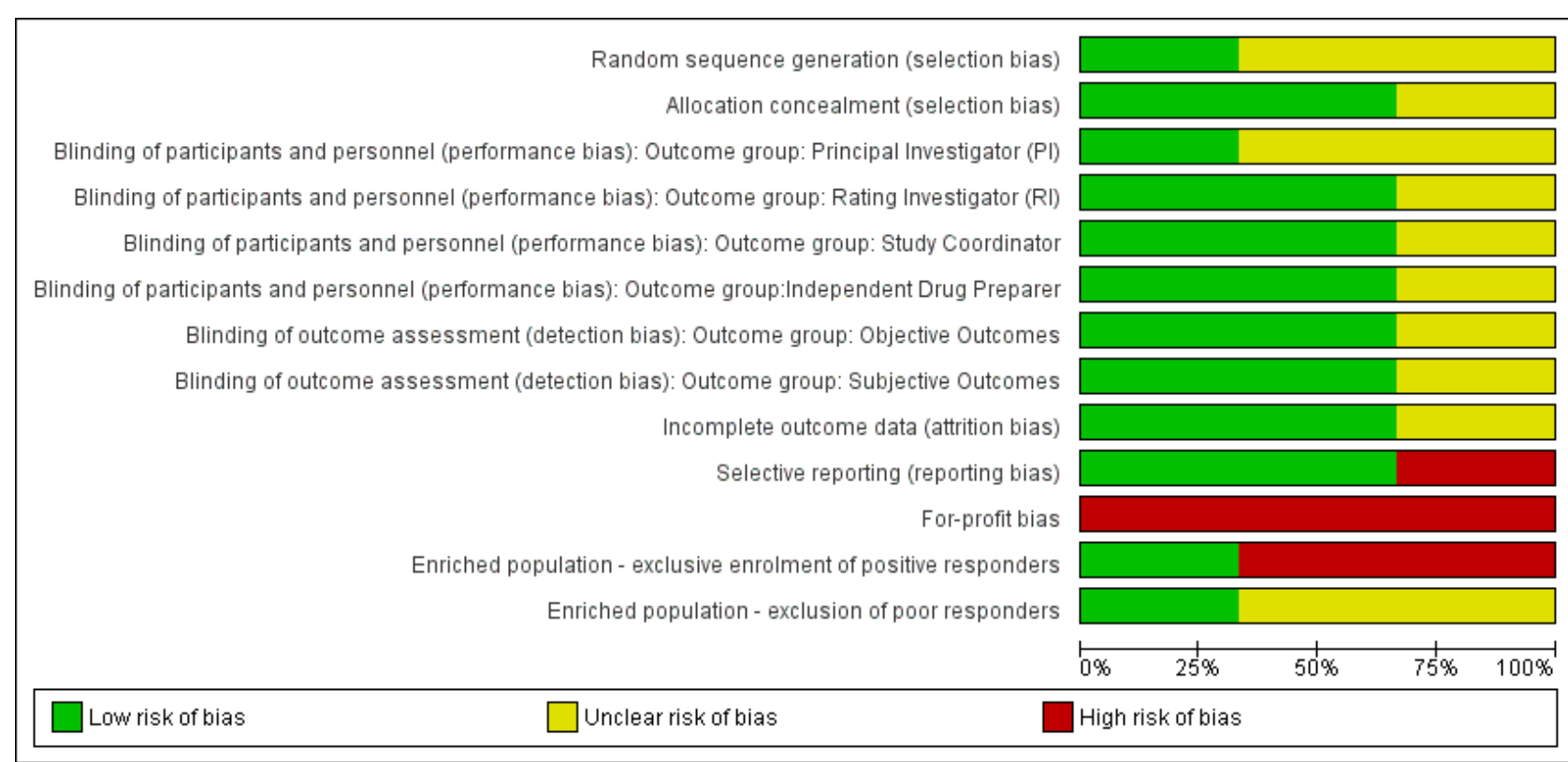


Figure 3. Risk of bias summary: review authors' judgements about each risk of bias item for each included study.

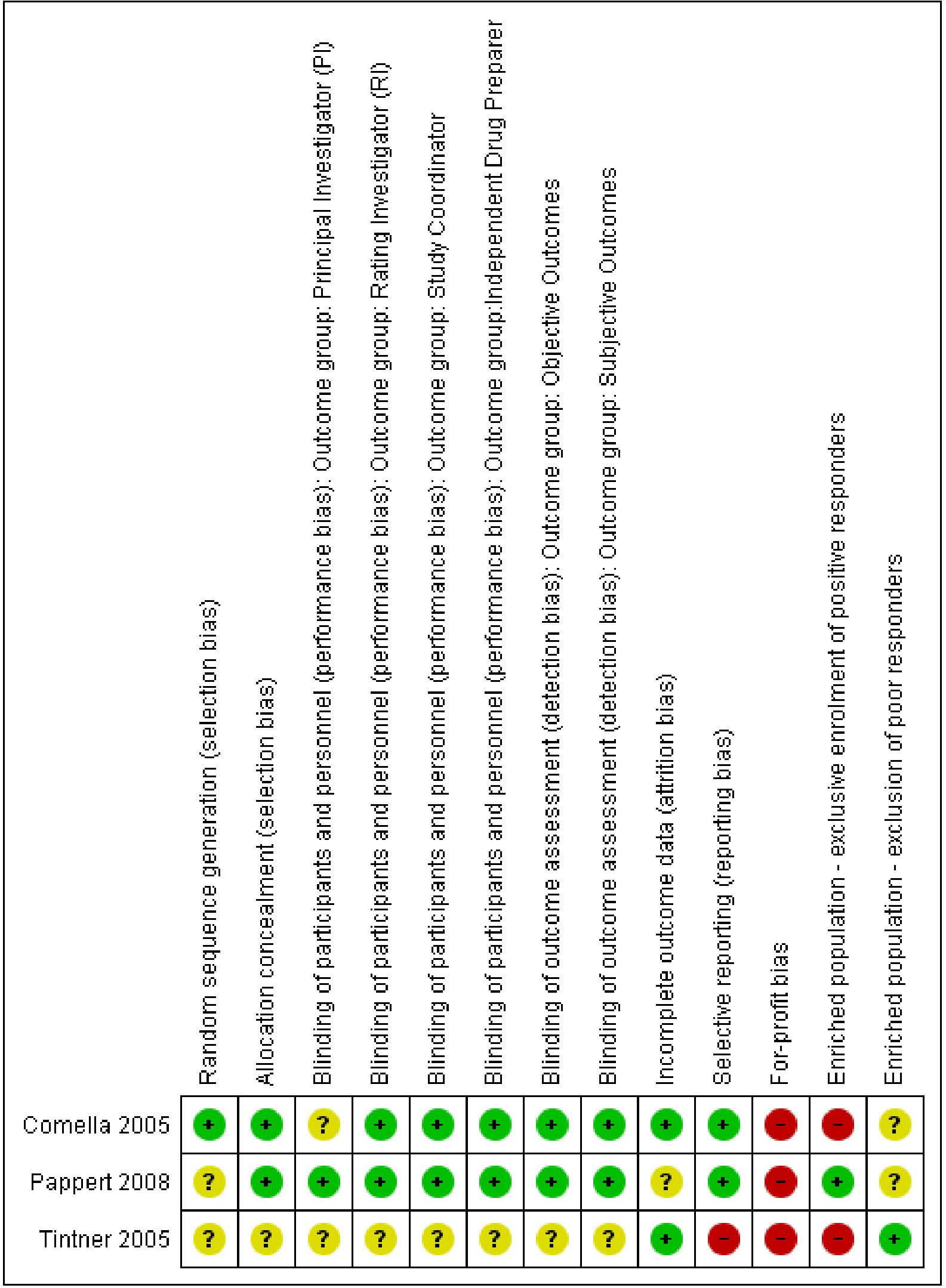


We considered that none of the included studies had a high risk of bias in all domains, though we rated the 'for-profit bias' domain at a high risk of bias in all studies, and considered the 'selective reporting' domain at a high risk of bias in one study (Tintner 2005). We additionally rated all studies to as having a low risk of bias with regard to the incomplete outcome data domain.

\section{Allocation}

Comella 2005 adequately described the method of randomisation (permuted block allocation scheme), though made no specific description of allocation concealment. We chose to rate Comella 2005 as having a low risk of selection bias. We considered that the remaining studies had an unclear risk of bias (Pappert 2008; Tintner 2005), as no specific and reproducible descriptions were made regarding the methods of randomisation and allocation concealment.

\section{Blinding}

Two studies adequately reported the methods of guaranteeing blinding, being correctly executed, double-blind controlled trials, so we rated them as having a low risk of bias (Comella 2005; Pappert 2008). We rated the remaining study as having an unclear risk of bias (Tintner 2005).

\section{Incomplete outcome data}

Two studies adequately reported the number and reasons for participant exclusions in both treatment arms (Comella 2005; Tintner 2005), these were evenly distributed across both treatment arms, and so we rated them as having a low risk of bias. Pappert 2008 did not provide data according to an ITT principle, so we chose to grade this study as being at an uncertain risk of attrition bias.

\section{Selective reporting}

We considered that the more clinically relevant outcomes that are usually evaluated in intervention trials for this condition were reported in both Comella 2005 and Pappert 2008, which is why they were considered to be at low risk of bias for reporting data. We rated the remaining study as having a high risk of bias for this domain (Tintner 2005). This is because it referred in the methods section to having selected several outcomes, though only two of these were reported in the results. Additionally, none of the included studies had a registered trial protocol available.

\section{Other potential sources of bias}

\section{For-profit bias}

All studies were supported, wholly or in part, by pharmaceutical companies (Allergan, Inc and Soltice Neurosciences, Inc) (Comella 2005; Pappert 2008; Tintner 2005).

\section{Enriched population}

We believe that all included studies potentially had a form of enriched population. Two studies exclusively enrolled positive responders to treatment with BtA (Comella 2005; Tintner 2005), meaning that there was a potential risk of population enrichment in 159 of the 270 participants (59\%) included in this review. These two studies also excluded people known to have poorer responses to treatment with botulinum toxin (Comella 2005; Pappert 2008), namely people with pure anterocollis and retrocollis.

\section{Publication bias}

We intended to use funnel plots to explore publication bias. However, due to the small number of included studies, the power of this analysis was considered to be inadequate (Sterne 2011).

\section{Effects of interventions}

See: Summary of findings for the main comparison Botulinum toxin type $A$ versus botulinum toxin type $B$ for adults with cervical dystonia

The key results of this review can be found in 'Summary of findings for the main comparison'.

\section{Preceding data analysis}

See Dealing with missing data.

In this review we derived the values of the change from baseline SD for each of the TWSTRS sub-scales (pain, severity and disability) in Tintner 2005. In this case we created a correlation coefficient for each sub-scale based on Pappert 2008, and then used this to impute the change from baseline SD for each sub-scale, for both BtA and BtB. Since Pappert 2008 did not report the final SD for each intervention group we opted to substitute it with the baseline SD, as it is reasonable to assume that the intervention does not alter the variability of the outcome measure (Higgins 2011c). In all cases the correlation coefficient was greater than 0.5 , which provides added security to our imputation.

We had no further need to use imputation methods.

We conducted sensitivity analyses for each case in which imputation methods were applied.

\section{Primary outcomes}

\section{Overall improvement on any validated symptomatic rating scale for cervical dystonia}

The Toronto Western Spasmodic Torticollis Rating Scale (TWSTRS) is currently the most common clinical validated tool to assess and document the status of people with cervical dystonia (Consky 1994). The TWSTRS (total score range, 0 to 85 ) is composite of three sub-scales that evaluate different features of cervical dystonia, namely severity (range, 0 to 35), disability (range, 0 to 30) and pain (range, 0 to 20). The higher the score, the greater the level of morbidity. In the absence of a validated value for a clinically meaningful change in TWSTRS total score, we have considered a $10 \%$ change from participants' baseline status as representing a clinically meaningful change.

Two studies $(n=231)$ reported data for the mean change from baseline in TWSTRS total score (Comella 2005; Pappert 2008), with no difference between the BtA and BtB treatment groups, mean difference (MD) $-1.44\left(95 \% \mathrm{Cl}-3.58\right.$ to $0.70 ; 1^{2}=0 \%$; Analysis 1.1 ; Figure 4). 
Figure 4. Forest plot of comparison: 1 Botulinum toxin type A versus botulinum toxin type B, outcome: 1.1 Overall cervical dystonia improvement as assessed with validated scales: change from baseline to week 4.

\begin{tabular}{|c|c|c|c|c|c|c|c|c|c|c|}
\hline \multirow[b]{2}{*}{ Study or Subgroup } & \multicolumn{3}{|c|}{ BtA } & \multicolumn{3}{|c|}{ BtB } & \multicolumn{3}{|c|}{ Mean Difference } & \multirow{2}{*}{$\begin{array}{c}\text { Mean Difference } \\
\text { IV, Random, } 95 \% \mathrm{Cl}\end{array}$} \\
\hline & Mean & SD & Total & Mean & SD & Total & Weight & IV, Random, 95\% Cl & Year & \\
\hline Comella 2005 (1) & 9.3 & 8.3 & 73 & 10.2 & 8.4 & 65 & $58.7 \%$ & $-0.90[-3.69,1.89]$ & 2005 & 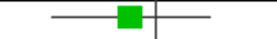 \\
\hline Pappert 2008 (2) & 8.8 & 8.2268 & 47 & 11 & 8.1388 & 46 & $41.3 \%$ & $-2.20[-5.53,1.13]$ & 2008 & \\
\hline Total $(95 \% \mathrm{Cl})$ & & & 120 & & & 111 & $100.0 \%$ & $-1.44[-3.58,0.70]$ & & \\
\hline \multicolumn{10}{|c|}{$\begin{array}{l}\text { Heterogeneity: } \operatorname{Tau}^{2}=0.00 ; \mathrm{Chi}^{2}=0.34, \mathrm{df}=1(P=0.56) ; \mathrm{I}^{2}=0 \% \\
\text { Test for overall effect: } Z=1.32(P=0.19)\end{array}$} & $\begin{array}{ccccc}-4 & 1 & 1 & 1 & 1 \\
\text { Favours BtB } & \text { Favours B }\end{array}$ \\
\hline
\end{tabular}

(1) Change in total TWSTRS score at week 4. Botox $250 \mathrm{U}$; Myobloc $10000 \mathrm{U}$.

(2) Adjusted mean change in total TWSTRS score at week 4. BtA 150 U; BtB 10000 U. SE -> SD

In relation to the trial sequential analysis, the cumulative evidence overcame the information size generated by a conventional sample size calculation, assuming a baseline TWSTRS of 40 points and a required change of $10 \%$ from baseline, with an SD of 8.3 . The cumulative evidence also overcame the heterogeneity-adjusted required information size of 138 participants.

We were able to use data from all three included studies to calculate the improvement on TWSTRS sub-scales, with there being no difference between the $\mathrm{BtA}$ and $\mathrm{BtB}$ groups with regard to both TWSTRS severity (MD $-0.26 ; 95 \% \mathrm{Cl}-1.27$ to $0.75 ; \mathrm{I}^{2}=0 \%$; Analysis 1.2) and TWSTRS disability (MD $-0.17 ; 95 \% \mathrm{Cl}-1.19$ to $0.86 ; \mathrm{I}^{2}=0 \%$; Analysis 1.3).

\section{Proportion of participants with adverse events}

One study $(n=111)$ reported data concerning the proportion of participants with adverse events (Pappert 2008). In this study BtA and $\mathrm{BtB}$ treatment were not associated with different risks for adverse events (RR 1.40; $95 \% \mathrm{Cl} 1.00$ to 1.96; Analysis 1.4).

We were not able to calculate a heterogeneity-adjusted required information size for this outcome since it was only reported in one study. However, the total number of participants included in this trial was less than the number generated by a conventional sample size calculation for a single adequately powered equivalence trial. Therefore, the cumulative evidence was not adequately powered for evaluation of the proportion of participants with adverse events.

\section{Secondary outcomes}

Change in subjective evaluation of clinical status evaluated both by patients and clinicians

One study (138 participants) reported data with regard to subjective assessments by both clinicians and patients at week 4 after treatment. (Comella 2005) The instruments used to measure this outcome were the Patient Global Assessment (PGA) and Subjective Global Assessment (SGA) scales. The PGA and SGA ratings ranged from -4 (marked worsening of cervical dystonia signs) to 4 (complete abolishment of cervical dystonia signs).

Both forms of subjective assessment, measured as mean change from baseline in PGA and SGA, were not different between BtA and BtB groups, (PGA MD 0.20; $95 \% \mathrm{Cl}-0.17$ to 0.57 ; Analysis 1.5; SGA MD $0.20 ; 95 \% \mathrm{Cl}-0.20$ to 0.60 ; Analysis 1.6 ).

Pappert 2008 also mentioned having studied subjective evaluation of clinical status by both patients and clinicians, though the final report did not include any data for this analysis, referring only to the fact that all evaluations were similar between treatment arms.

\section{Changes in pain scores, as assessed with validated assessment tools}

All included trials provided data in the form of mean change from baseline on TWSTRS pain sub-scale (range, 0 to 20); there was no difference between the intervention groups for this outcome (MD $-0.83 ; 95 \% \mathrm{Cl}-1.75$ to $0.09 ; \mathrm{I}^{2}=0 \%$; Analysis 1.7 ).

\section{Changes in quality of life assessments}

None of the included trials studied the effect of BtA or BtB on the quality of life of people with cervical dystonia.

\section{Proportion of participants with adverse events of special interest}

The most frequently reported adverse events were sore throat/ dry mouth (24.5\%) (Comella 2005; Pappert 2008), and dysphagia (18.2\%) (Comella 2005; Pappert 2008; Tintner 2005). Dysphagia was equally likely in BtA and BtB-treated participants (RR 2.89; 95\% $\mathrm{Cl} 0.80$ to 10.41 ; $\left.\right|^{2}=74 \%$; Analysis 1.9). Sore throat/dry mouth was more likely among BtB-treated participants in comparison to BtAtreated ones, with a RR of $4.39(95 \% \mathrm{Cl} 2.43$ to $7.91 ; 12=0 \%$; Analysis 1.8). The NNTH in BtB-treated participants compared to BtA-treated participants for sore throat/dry mouth was 3 ( $95 \% \mathrm{Cl} 4$ to 2 ).

For all other reported adverse events, including pain at injection site, no difference was found between groups.

\section{Duration of effect, or number of days until need for reinjection or effect waning}

This item was reported in two studies $(n=231)$ (Comella 2005; Pappert 2008), though we opted not to combine the data through a quantitative synthesis (meta-analysis) due to this outcome being reported as survival time for the median of each arm with the inherent limitations that entails (Michiels 2005).

Pappert 2008 reported that among its 93 participants both formulations of Bt did not differ from one another - median treatment duration of effect was 13.1 weeks in the BtA arm and 13.7 weeks in the $\mathrm{BtB}$ arm (hazard ratio (HR) $0.95 ; 95 \% \mathrm{Cl} 0.56$ to 1.59 ; $\log$ rank $P=0.833)$. The trialists performed a subgroup analysis for participants who showed an improvement from baseline at week $4(n=83)$ was also conducted, without a difference between the groups (HR 0.79; $95 \% \mathrm{Cl} 0.45$ to 1.41 ; $\log$ rank $\mathrm{P}=0.414$ ). 
Similarly, Comella 2005 reported that among its 138 participants both formulations of Bt did not differ from one another - median treatment duration of effect was 13.0 weeks in the BtA arm and 11.7 weeks in the BtB arm ( $\mathrm{HR} 95 \% \mathrm{Cl} 0.55$ to 1.07). A subgroup analysis for participants who showed an improvement from baseline at week 4 was also conducted, with a median time to loss of benefit of 14 weeks for BtA and 12.1 weeks for BtB. The trialists presented the results of a log rank test for this subgroup reporting a difference in the two distributions (HR 95\% Cl 0.43 to 0.98).

\section{DISCUSSION}

\section{Summary of main results}

This updated review included three randomised, parallel-designed trials, that enrolled 270 participants with cervical dystonia, of whom $62.3 \%$ had been previously treated with botulinum toxin type A (BtA). As can be seen in the Summary of findings for the main comparison, $\mathrm{Bt} A$ (onabotulinumtoxinA) and botulinum toxin type $B$ ( $B t B$; rimabotulinumtoxin $B$ ) were equally effective in reducing overall disease impairment, including disease severity, disability, and pain. Subjective assessments by both participants and clinicians were likewise not different between BtA and BtB. The comparative impacts of both forms of botulinum toxin on other domains of participants' quality of life, such as social functioning or mental health, have not been addressed in the included trials.

Overall adverse event rates were not different between groups, though this may be due to the small sample that was analysed for this outcome. The short duration of the trials, as well as the reduced sample size, precluded the drawing of strong conclusions regarding the lack of differences between $\mathrm{Bt} A$ and $\mathrm{Bt} B$. The most common adverse events of special interest related to treatment were sore throat/dry mouth and dysphagia. Of these, only the risk of sore throat/dry mouth was different between the treatment groups, with BtB-treated participants experiencing an increased risk of this adverse event, with a number needed to treat for one additional harmful event of 3 after a single botulinum toxin (Bt) injection. No fatalities or serious adverse events were considered to be related to either treatment in any of the trials. Data for special subpopulations, such as people with certain types of cervical dystonia known to respond poorly to Bt treatment, as well as for children and pregnant women, were not available.

We found low-to-moderate statistical heterogeneity for most efficacy and safety outcome estimates, the exception being dysphagia.

\section{Overall completeness and applicability of evidence}

All included trials addressed the primary research question directly, using the same assessment tool, the Toronto Western Spasmodic Torticollis Rating Scale (TWSTRS). However, data were not fully reported for all outcomes, and in some cases results could not be pooled and compared across studies. This limited the amount of data available and, consequently, our confidence in the overall conclusions.

The participants included in the studies were not fully representative of the overall population of people with cervical dystonia. The effects of population enrichment and the moderate overall disease impairment (as assessed by the baseline TWSTRS scores) preclude definite conclusions concerning all people with this condition.
Since the included trials use only onabotulinumtoxinA, there are no data regarding the efficacy and safety profile of BtB versus other forms of BtA, namely abobotulinumtoxinA and incobotulinumtoxinA.

Four noteworthy factors challenge the implementation of the evidence derived from this review. Firstly, a limited number of centres conducted the research, and these were heterogeneous in terms of their regional distribution, with all trials being conducted in Europe or North America. Differences in clinical practice, training of experts, and local guidelines in other regions of the world may conceivably present an obstacle to application of the evidence summarised here. Secondly, the total number of participants across several outcomes was less than the number of participants calculated by a standard sample size calculation for a single adequately powered equivalence study. As such, presenting only trends in the results, more studies are needed to provide robust evidence with regards to these trends. Thirdly, it is common for people with cervical dystonia to have concomitant medications for their condition, such as muscle relaxants and benzodiazepines. Reasonably, in trials, participants are required to be on a stable dose of these medications for many weeks to avoid confounding factors. As a result, little is known at present about the impact of these drug regimens with regard to implementation of the evidence in this review. Fourthly, several outcomes of interest were either poorly reported or entirely omitted. Specifically, no quality of life assessments were reported in any of the included studies; subjective assessments by both participants and clinicians were not reported in two of the included studies; the proportion of participants with adverse events was also not reported in two of the included studies; and the time to effect was not reported in any of the included trials, which is of interest as this is clinically relevant for both participants and clinicians, as well as a potentially important differentiating factor between BtA and BtB.

\section{Quality of the evidence}

See Characteristics of included studies, 'Risk of bias' tables, and 'Risk of bias' summary tables (Figure 2; Figure 3).

We considered all studies to be at high risk of bias due to forprofit bias. We additionally considered Tintner 2005 to be at a high risk of reporting bias, since it did not report outcomes that were collected, without providing any explanation for this omission. Additionally, we judged Tintner 2005 to be at an unclear risk of bias for all 'Risk of bias' domains with the exception of attrition bias. We considered the risk of bias due to an enriched population to be high in Comella 2005 and Tintner 2005, and unclear in Pappert 2008. Finally, statistical heterogeneity was low for all outcomes with the exception of the proportion of participants with sore throat/dry mouth.

Some outcomes could not be compared across studies, as some studies lacked reporting of relevant data. Imbalances between baseline characteristics of the participants and incomplete description of the variables prevented confident imputation of values for missing data, which further reduced the amount of combinable data, and therefore the precision of the results.

The included trials enrolled between 20 and 139 participants, each individually enrolling fewer participants than the total number that would be required for a single adequately-powered equivalence trial of BtA versus BtB. Collectively however, only the following 
outcomes were under-powered: overall proportion of participants with adverse events, change in subjective evaluation of clinical status evaluated by patients, and changes in pain scores.

Taken together, as can be seen in Summary of findings for the main comparison, we consider that there is low quality evidence that a single treatment session of $\mathrm{BtA}$ and a single treatment session of $\mathrm{BtB}$, in certain types of cervical dystonia, are equally efficacious in reducing disease impairment, including severity, disability, and pain. The quality of evidence supporting the higher occurrence of sore throat/dry mouth among BtB-treated individuals is moderate. There is also low-quality evidence that dysphagia occurs at the same rate in people treated with BtA and BtB. The quality of evidence assessing the change in subjective evaluation of clinical status evaluated by patients is low. Regarding the overall safety and tolerability comparison, the quality of the evidence is low, meaning that we are unable to draw any robust conclusions. Additionally, we can draw no conclusions regarding continued responsiveness and long-term efficacy, which are important aspects to consider in a chronic condition such as cervical dystonia.

\section{Potential biases in the review process}

Although we followed the methods recommended by Cochrane in order to minimise bias in the review process, certain areas do deserve attention. Despite having contacted experts in the area extensively, not having searched all available clinical trial registries opens the current review to two potential problems: firstly, the possibility of having missed trials and also the possibility of introducing publication bias. We opted not to search trial registries as the trials that have been conducted are well-known in the area, and this form of search was not included in the review protocol.

An additional bias was that we could not obtain data for all outcomes in the included trials. A further limitation of this review is the small number of participants contributing data to each outcome. Therefore, the results of the pooled analysis should be viewed with caution, especially in the presence of statistical heterogeneity, as further studies may have an important impact in effect size estimations.

\section{Agreements and disagreements with other studies or reviews}

The current review is, to our knowledge, the first systematic review with data that address the question of whether one type of botulinum toxin is superior to another or not. We have included all randomised controlled trials that addressed this question in the current review.

Comella 2005 reported a very large proportion of BtB-treated participants with dysphagia and sore throat/dry mouth at week 4, particularly when compared to the available evidence from RCTs (dysphagia in Comella 2005: 80\%; dysphagia in Marques 2016: 16\%; sore throat/dry mouth in Comella 2005: 48\%; sore throat/ dry mouth in Marques 2016: 17\%). However, the participants with these adverse events at baseline was likewise very high (baseline dysphagia in Comella 2005: 14\%; baseline sore throat/dry mouth in Comella 2005: 37\%), as the study exclusively enrolled people already being treated with BtA for cervical dystonia. For this reason, we opted to study the proportion of newly-developed cases of each adverse event in comparison to baseline, with the results being more in-line with both the available evidence and clinical practice
(See Table 2 for a comparison of dysphagia and sore throat/dry mouth in Comella 2005, Marques 2016, and the current review).

\section{AUTHORS' CONCLUSIONS}

\section{Implications for practice}

In this updated Cochrane Review we found that a single treatment session of BtA and a single treatment session of BtB are equally effective and well tolerated in the treatment of adults with certain types of cervical dystonia. Treatment with BtB is associated with an increased risk of sore throat/dry mouth when compared to treatment with BtA. Overall, there is no clinical evidence to support or not support the preferential use of one form of botulinum toxin over another. No conclusions can be drawn regarding individuals with predominant retrocollis or anterocollis, as these were mostly excluded from the clinical trials.

\section{Implications for research}

We have had access only to published research data from trials of botulinum toxin type $A(B t A)$ versus $B t B$ in cervical dystonia. It is difficult to determine which and how many resources should be invested in future research.

It would be of interest if future studies comparing $B t A$ and $B t B$ were to use different formulations of $B t A$, namely abobotulinumtoxinA or incobotulinumtoxinA, or both, as the trials included in this review used only onabotulinumtoxinA.

The net benefit of both a single BtA and BtB injection in the treatment of cervical dystonia has been established in the published trials. Nonetheless, further studies are needed to establish the relative effectiveness of different doses of specific botulinum toxin formulations, assessing efficacy, safety, duration of effect and quality of life across regimes. Because therapy typically requires optimising a dose for each patient rather than administering a fixed dose of botulinum toxin, such a line of research would be important to support physicians' management of doses and allow for a more solid and safe individualisation of patient treatment. Also to be determined is the added value, if any, of guidance methods (e.g. electromyography) in injecting botulinum toxin into the cervical muscles.

The time to effect of BtA and BtB were not studied in any of the included studies, and as this may be a clinically relevant and differentiating factor between the two formulations, future research should endeavour to study this outcome.

Future research concerning all formulations of botulinum neurotoxin should endeavour to establish clinical effectiveness not only based on changes from baseline, but also, preferably, based on validated measures of Minimal Clinically Important Difference/ Change (Brożek 2006). Research is required in order to establish such a parameter for the Toronto Western Spasmodic Torticollis Rating Scale (TWSTRS), currently the most widely used and disseminated clinical scale in the field. We are, however, aware of an effort to create a new clinical scale in dystonia - the Comprehensive Cervical Dystonia Rating Scale (Comella 2015), which will include a revision of the TWSTRS, to be named TWSTRS-2, with a Minimal Clinically Important Change validation being planned.

It is currently uncertain whether or not the clinical effectiveness of botulinum toxin decays over time, with repeated treatment 
sessions, and whether a possible loss of effectiveness occurs in all clinical domains. Another related aspect is the possible development of BtB-non-responsiveness, as there is no plausible theoretical reason why this would not occur, as it does for BtA. Future studies comparing BtA and BtB should address the comparative proportion of participants who develop clinical secondary non-responsiveness to treatment.

Finally, in conducting this systematic review we were faced with the fact that there is no defined core outcome set in cervical dystonia research, as there are for other areas (Tugwell 2007). The definition of a set of core outcome measures to be included in future research, via well-established methodology to determine the inclusion of patient-reported outcomes (Macefield 2014), would be relevant to promote research in this field, as well as to support the clinical effectiveness of botulinum toxin.

\section{ACKNOWLEDGEMENTS}

We would like to thank Ema Roque (Cochrane Movement Disorders Review Group), Daisy Abreu (Clinical Pharmacology Unit, Faculty of Medicine, University of Lisbon), and Francesca Fiorentino (CEMBE, Faculty of Medicine, University of Lisbon) sincerely for their contributions to this review. Additionally, we would like to thank the internal peer-reviewers, who greatly added to the quality of this review. 


\section{R E F E R E N C E S}

\section{References to studies included in this review}

Comella 2005 \{published data only\}

Comella CL, Jankovic J, Shannon KM, Tsui J, Swenson M, Leurgans $S$, et al. Comparison of botulinum toxin serotypes $A$ and $B$ for the treatment of cervical dystonia. Neurology 2005;65:1423-9. [DOI: 10.1212/01.wnl.0000183055.81056.5c]

\section{Pappert 2008 \{published data only\}}

Pappert EJ, Germanson T. Botulinum toxin type B vs. type A in toxin-naïve patients with cervical dystonia: randomized doubleblind, noninferiority trial. Movement Disorders 2008;23:510-7.

\section{Tintner 2005 \{published data only\}}

Tintner R, Gross R, Winzer UF, Smalky KA, Jankovic J. Autonomic function after botulinum toxin type A or B: a double-blind, randomized trial. Neurology 2005;65:765-7.

\section{Additional references}

\section{Abrams 2005}

Abrams KR, Gillies CL, Lambert PC. Meta-analysis of heterogeneously reported trials assessing change from baseline. Statistics in Medicine 2005;24:3823-44.

\section{Albanese 2013}

Albanese A, Bhatia K, Bressman SB, Delong MR, Fahn S, Fung VS, et al. Phenomenology and classification of dystonia: a consensus update. Movement Disorders 2013;28(7):863-73.

\section{Altman 2002}

Altman DG, Deeks JJ. Meta-analysis, Simpson's paradox, and the number needed to treat. BMC Medical Research Methodology 2002;2(1):3.

\section{Antonucci 2008}

Antonucci F, Rossi C, Gianfranceschi L, Rossetto O, Caleo M. Long-distance retrograde effects of botulinum neurotoxin. Journal of Neuroscience 2008;28:3689-96.

\section{Balint 2015}

Balint B, Bhatia KP. Isolated and combined dystonia syndromes - an update on new genes and their phenotypes. European Journal of Neurology 2015;22(4):610-7.

\section{Balshem 2011}

Balshem H, Helfand M, Schünemann HJ, Oxman AD, Kunz R, Brozek J, et al. GRADE guidelines: 3. Rating the quality of evidence. Journal of Clinical Epidemiology 2011;64(4):401-6.

\section{Benecke 2012}

Benecke R. Clinical Relevance of Botulinum Toxin Immunogenicity. BioDrugs 2012;26(2):e1-e9.

\section{Bentivoglio 2015}

Bentivoglio AR, Del Grande A, Petracca M, Tamara lalongo T, Ricciardi L. Clinical differences between botulinum neurotoxin type A and B. Toxicon 2015;107:77-84. [DOI: http:// dx.doi.org/10.1016/j.toxicon.2015.08.001]

\section{BNF 2016a}

British National Formulary. Botulinum toxin type A. National Institute for Health and Care Excellence May 2016. [http:// www.evidence.nhs.uk/formulary/bnf/current/4-centralnervous-system/49-drugs-used-in-parkinsonism-and-relateddisorders/493-drugs-used-in-essential-tremor-chorea-tics-andrelated-disorders/torsion-dystonias-and-other-involuntarymovements/botulinum-toxin-type-a]

\section{BNF 2016b}

British National Formulary. Botulinum toxin type B. National Institute for Health and Care Excellence May 2016. [http:// www.evidence.nhs.uk/formulary/bnf/current/4-centralnervous-system/49-drugs-used-in-parkinsonism-and-relateddisorders/493-drugs-used-in-essential-tremor-chorea-tics-andrelated-disorders/torsion-dystonias-and-other-involuntarymovements/botulinum-toxin-type-b]

\section{Boroff 1975}

Boroff DA, Chen GS. On the question of permeability of the blood-brain barrier to botulinum toxin. International Archives of Allergy and Applied Immunology 1975;48:495-504.

\section{Brashear 2008}

Brashear A. Botulinum toxin serotype A for cervical dystonia-an assessment. US Neurology 2008;4(2):58-61.

\section{Brin 2008}

Brin MF, Comella CL, Jankovic J, Lai F, Naumann M, CD-017 BoNTA Study Group. Long-term treatment with botulinum toxin type $A$ in cervical dystonia has low immunogenicity by mouse protection assay. Movement Disorders 2008;23(10):1353-60.

\section{Brożek 2006}

Brożek JL, Guyatt GH, Schünemann HJ. How a well-grounded minimal important difference can enhance transparency of labelling claims and improve interpretation of a patient reported outcome measure. Health and Quality of Life Outcomes 2006;4:69.

\section{Carpenter 2013}

Carpenter J, Kenward M. Multiple Imputation and its Application. Wiley, 2013.

\section{Chan 1991}

Chan J, Brin MF, Fanh S. Idiopathic cervical dystonia: clinical characteristics. Movement Disorders 1991;6:119-26.

\section{Cohen 1988}

Cohen J. Statistical Power Analysis in the Behavioral Sciences. 2nd Edition. Hillsdale (NJ): Lawrence Erlbaum Associates, Inc, 1988.

\section{Comella 2015}

Comella CL, Fox SH, Bhatia KP, Perlmutter JS, Jinnah HA, Zurowski M, et al. Development of the comprehensive Cervical Dystonia Rating Scale: methodology. Movement Disorders 2015;2(2):135-41. 


\section{Consky 1994}

Consky ES, Lang AE. Clinical assessments of patients with cervical dystonia. In: Jankovic J, Hallett M editor(s). Therapy with Botulinum Toxin. New York (NY): Marcel Dekker, Inc, 1994:211-37.

\section{Corbett 2014}

Corbett MS, Higgins JP, Woolacott NF. Assessing baseline imbalance in randomised trials: implications for the Cochrane risk of bias tool. Research Synthesis Methods 2014;5(1):79-85.

\section{Costa 2005}

Costa J, Espírito-Santo C, Borges A, Ferreira JJ, Coelho M, Moore $P$, et al. Botulinum toxin type A therapy for cervical dystonia. Cochrane Database of Systematic Reviews 2005, Issue 1. [DOI: 10.1002/14651858.CD003633.pub2; PUBMED: 15674910]

\section{Cullis 2000}

Cullis PA, Barnes M, Duane D, Chen RE, Freeman A, Fross R, et al. Safety and tolerability of repeated doses of Neurobloc (Botulinum toxin type B) in patients with cervical dystonia: an open-label, dose-escalation study. Movement Disorders 2000;15 (Suppl 2):29.

\section{de Paiva 1999}

de Paiva A, Meunier FA, Molgó J, Aoki KR, Dolly JO. Functional repair of motor endplates after botulinum neurotoxin type A poisoning: biphasic switch of synaptic activity between nerve sprouts and their parent terminals. Proceedings of the National Academy of Sciences of the United States of America 1999;96:3200-5.

\section{Defazio 2013}

Defazio G, Jankovic J, Giel JL, Papapetropoulos S. Descriptive epidemiology of cervical dystonia. Tremor and Other Hyperkinetic Movements 2013;3:tre-03-193-4374-2.

\section{Duchen 1971}

Duchen LW. An electron microscopic study of the changes induced by botulinum toxin in the motor end-plates of slow and fast skeletal muscle fibres of the mouse. Journal of the Neurological Sciences 1971;14:47-60.

\section{Eleopra 1997}

Eleopra R, Tugnoli V, Rossetto O, Montecucco C, De Grandis D. Botulinum neurotoxin serotype $\mathrm{C}$ : a novel effective botulinum toxin therapy in human. Neuroscience Letters 1997;224(2):91-4.

\section{ESDE 2000}

Epidemiological Study of Dystonia in Europe (ESDE) Collaborative Group. A prevalence study of primary dystonia in eight European countries. Journal of Neurology 2000;247:787-92.

\section{Fabbri 2015}

Fabbri M, Leodori G, Fernandes RM, Bhidayasiri R, Marti MJ, Colosimo C, et al. Neutralizing antibody and botulinum toxin therapy: a systematic review and meta-analysis. Neurotoxicity Research 2015;29:105-17. [PUBMED: 26467676]

\section{Filippi 1993}

Filippi GM, Errico P, Santarelli R, Bagolini B, Manni E. Botulinum A toxin effects on rat jaw muscle spindles. Acta Otolaryngologica 1993;113:400-4.

\section{Follmann 1992}

Follmann D, Elliott P, Suh I, Cutler J. Variance imputation for overviews of clinical trials with continuous response. Journal of Clinical Epidemiology 1992;45:769-73.

\section{Foltz 1959}

Foltz EL, Knopp LM, Ward AA. Experimental spasmodic torticollis. Journal of Neurosurgery 1959;16:55-72.

\section{Frevert 2010}

Frevert J, Dressler D. Complexing proteins in botulinum toxin type A drugs: a help or a hindrance?. Biologics: Targets \& Therapy 2010 Dec;4:325-32.

\section{Furukawa 2006}

Furukawa TA, Barbui C, Cipriani A, Brambilla P, Watanabe N. Imputing missing standard deviations in meta-analyses can provide accurate results. Journal of Clinical Epidemiology 2006;59(1):7-10.

\section{GRADEpro GDT 2014 [Computer program]}

GRADE Working Group, McMaster University. GRADEpro GDT. Version Date accessed: September 2016. Hamilton (ON): GRADE Working Group, McMaster University, 2014.

\section{Greene 1993}

Greene PE, Fahn S. Use of botulinum toxin type F injections to treat torticollis in patients with immunity to botulinum toxin type A. Movement Disorders 1993;8(4):479-83.

\section{Guyatt 2011}

Guyatt GH, Oxman AD, Kunz R, Brozek J, Alonso-Coello P, Rind $D$, et al. GRADE guidelines 6 . Rating the quality of evidence - imprecision. Journal of Clinical Epidemiology 2011;64(12):1283-93.

\section{Hallett 1998}

Hallett M. The neurophysiology of dystonia. Archives of Neurology 1998;55(5):601-3.

\section{Hanna 1998}

Hanna PA, Jankovic J. Mouse bioassay versus western blot assay for botulinum toxin antibodies: correlation with clinical response. Neurology 1998;50(6):1624-9.

\section{Hedges 1985}

Hedges LV, Olkin I. Statistical Methods for Meta-Analysis. Academic Press, Inc, 1985.

\section{Higgins 2003}

Higgins JPT, Thompson SG, Deeks JJ, Altman DG. Measuring inconsistency in meta-analyses. BMJ 2003;327(7414):557-60.

\section{Higgins 2011a}

Higgins JP, Deeks JJ editor(s). Chapter 7: Selecting studies and collecting data. In: Higgins JPT, Green S editor(s). Cochrane 
Handbook for Systematic Reviews of Interventions Version 5.1.0 (updated March 2011). The Cochrane Collaboration, 2011. Available from handbook.cochrane.org.

\section{Higgins 2011b}

Higgins JPT, Altman DG, Sterne JAC editor(s). Chapter 8: Assessing risk of bias in included studies. In: Higgins JPT, Green S editor(s). Cochrane Handbook for Systematic Reviews of Interventions Version 5.1.0 (updated March 2011). The Cochrane Collaboration, 2011. Available from handbook.cochrane.org.

\section{Higgins 2011c}

Higgins JPT, Deeks JJ, Altman DG editor(s). Chapter 16: Special topics in statistics. In: Higgins JPT, Green S editor(s). Cochrane Handbook for Systematic Reviews of Interventions Version 5.1.0 (updated March 2011). The Cochrane Collaboration, 2011. Available from handbook.cochrane.org.

\section{Holland 1981}

Holland RL, Brown MC. Nerve growth in botulinum toxin poisoned muscles. Neuroscience 1981;6:1167-79.

\section{Imberger 2016}

Imberger G, Thorlund K, Gluud C, Wetterslev J. False-positive findings in Cochrane meta-analyses with and without application of trial sequential analysis: an empirical review. BMJ Open 2016;6(8):e011890.

\section{Jahanshani 1990}

Jahnanshani M, Marion M-H, Marsden CD. Natural history of adult-onset idiopathic torticollis. Archives of Neurology 1990;47:548-52.

\section{Jakobsen 2014}

Jakobsen JC, Wetterslev J, Winkel P, Lange T, Gluud C. Thresholds for statistical and clinical significance in systematic reviews with meta-analytic methods. BMC Medical Research Methodology 2014;14(1):120.

\section{Jankovic 2004}

Jankovic J. Botulinum toxin in clinical practice. Journal of Neurology, Neurosurgery, and Psychiatry 2004;75(7):951-7.

\section{Jankovic 2006}

Jankovic J, Tsui J, Bergeron C. Prevalence of cervical dystonia and spasmodic torticollis in the United States general population. Parkinsonism \& Related Disorders October 2007;13(7):411-6.

\section{Juzans 1996}

Juzans P, Comella J, Molgo J, Faille L, Angaut-Petit D. Nerve terminal sprouting in botulinum type-A treated mouse levator auris longus muscle. Neuromuscular Disorders 1996;6(3):177-85.

\section{Lange 2009}

Lange O, Bigalke H, Dengler R, Wegner F, deGroot M, Wohlfarth K. Neutralizing antibodies and secondary therapy failure after treatment with botulinum toxin type A: much ado about nothing?. Clinical Neuropharmacology 2009;32(4):213-8.

\section{Liberati 2009}

Liberati A, Altman DG, Tetzlaff J, Mulrow C, Gotzsche PC, loannidis JP, et al. The PRISMA statement for reporting systematic reviews and meta-analyses of studies that evaluate health care interventions: explanation and elaboration. PLOS Medicine 2009;6:e1000100.

\section{Macefield 2014}

Macefield RC, Jacobs M, Korfage IJ, Nicklin J, Whistance RN, Brookes ST, et al. Developing core outcomes sets: methods for identifying and including patient-reported outcomes (PROs). Trials 2014;15:49.

\section{Marques 2016}

Marques RE, Duarte GS, Rodrigues FB, Castelão M, Ferreira J, Sampaio C, et al. Botulinum toxin type B for cervical dystonia. Cochrane Database of Systematic Reviews 2016, Issue 5. [DOI: 10.1002/14651858.CD004315.pub3; PUBMED: 27176573]

\section{Matak 2014}

Matak I, Lacković Z. Botulinum toxin A, brain and pain. Progress in Neurobiology 2014;119-20:39-59.

\section{Matak 2015}

Matak I, Lacković Z. Botulinum neurotoxin type A: actions beyond SNAP-25?. Toxicology 2015;335:79-84.

\section{Michiels 2005}

Michiels S, Piedbois P, Burdett S, Syz N, Stewart L, Pignon JP. Meta-analysis when only the median survival times are known: a comparison with individual patient data results. International Journal of Technology Assessment in Health Care 2005;21(1):119-25.

\section{Müller 2009}

Müller K, Mix E, Adib Saberi F, Dressler D, Benecke R. Prevalence of neutralising antibodies in patients treated with botulinum toxin type A for spasticity. Journal of Neural Transmission 2009;116(5):579-85.

\section{O'Brien 1979}

O'Brien PC, Fleming TR. A multiple testing procedure for clinical trials. Biometrics 1979;35:549-56.

\section{Palomar 2012}

Palomar FJ, Mir P. Neurophysiological changes after intramuscular injection of botulinum toxin. Clinical Neurophysiology 2012;123(1):54-60.

\section{Pellizzari 1999}

Pellizzari R, Rossetto O, Schiavo G, Montecucco C. Tetanus and botulinum neurotoxins: mechanism of action and therapeutic uses. Philosophical Transactions of the Royal Society of London. Series B, Biological Sciences 1999;354:259-68.

\section{Peters 2006}

Peters JL, Sutton AJ, Jones DR, Abrams KR, Rushton L. Comparison of two methods to detect publication bias in metaanalysis. JAMA 2006;295(6):676-80. 


\section{RevMan 2014 [Computer program]}

The Nordic Centre, The Cochrane Collaboration. Review Manager (RevMan). Version 5.3. Copenhagen: The Nordic Centre, The Cochrane Collaboration, 2014.

\section{Rosales 1996}

Rosales RL, Arimura K, Takenaka S, Osame M. Extrafusal and intrafusal muscle effects in experimental botulinum toxin-A injection. Muscle \& Nerve 1996;19:488-96.

\section{Rosales 2010}

Rosales RL, Dressler D. On muscle spindles, dystonia and botulinum toxin. European Journal of Neurology 2010;17:71-80.

\section{Rubin 1991}

Rubin DB, Schenker N. Multiple imputation in health-care databases: an overview and some applications. Statistics in Medicine 1991;10:585-98.

\section{Schünemann 2011}

Schünemann HJ, Oxman AD, Higgins JPT, Vist GE, Glasziou P, Guyatt GH. Chapter 11: Presenting results and 'Summary of findings' tables. In: Higgins JPT, Green S editor(s), Cochrane Handbook for Systematic Reviews of Interventions Version 5.1.0 (updated March 2011). The Cochrane Collaboration, 2011. Available from handbook.cochrane.org.

\section{Simpson 2004}

Simpson LL. Identification of the major steps in botulinum toxin action. Annual Review of Pharmacology and Toxicology 2004;44:167-93.

\section{Smeeth 1999}

Smeeth L, Haines A, Ebrahim S. Numbers needed to treat derived from meta-analysis - sometimes informative, usually misleading. BMJ 1999;318(7197):1548-51.

\section{Stata 2015 [Computer program]}

StataCorp. Stata Statistical Software: release 14. Version Date accessed: September 2016. StataCorp, 2015.

\section{Steeves 2012}

Steeves TD, Day L, Dykeman J, Jette N, Pringsheim T. The prevalence of primary dystonia: a systematic review and metaanalysis. Movement Disorders 2012;27(14):1789-96.

\section{Sterne 2001}

Sterne JA, Egger M. Funnel plots for detecting bias in metaanalysis: guidelines on choice of axis. Journal of Clinical Epidemiology 2001;54(10):1046-55.

\section{Sterne 2011}

Sterne JAC, Egger M, Moher D editor(s). Chapter 10: Addressing reporting biases. In: Higgins JPT, Green S editor(s). Cochrane Handbook for Systematic Reviews of Intervention. Version 5.1.0 (updated March 2011). The Cochrane Collaboration, 2011. Available from handbook.cochrane.org.

\section{Tarsy 2006}

Tarsy D, Simon D. Dystonia. New Egyptian Journal of Medicine 2006;355:818-29.

\section{Thorlund 2011}

Thorlund K, Engstrøm J, Wetterslev J, Brok J, Imberger G, Gluud C. User manual for trial sequential analysis (TSA). ctu.dk/ tsa/files/tsa manual.pdf 2011.

\section{TSA 2011 [Computer program]}

Copenhagen Trial Unit. Trial Sequential Analysis. Version 0.9 Beta. Version Date accessed: September 2016. Copenhagen: Copenhagen Trial Unit, 2011.

\section{Tugwell 2007}

Tugwell P, Boers M, Brooks P, Simon L, Strand V, Idzerda L. OMERACT: an international initiative to improve outcome measurement in rheumatology. Trials 2007;8:38.

\section{Walker 2014}

Walker TJ, Dayan SH. Comparison and overview of currently available neurotoxins. Journal of Clinical and Aesthetic Dermatology 2014;7(2):31-9.

\section{Wetterslev 2008}

Wetterslev J, Thorlund K, Brok J, Gluud C. Trial sequential analysis may establish when firm evidence is reached in cumulative meta-analysis. Journal of Clinical Epidemiology 2008;61:64-75.

\section{Wetterslev 2009}

Wetterslev J, Thorlund K, Brok J, Gluud C. Estimating required information size by quantifying diversity in random-effects model meta-analyses. BMC Medical Research Methodology 2009;9:86.

\section{Wiebe 2006}

Wiebe N, Vandermeer B, Platt RW, Klassen TP, Moher D, Barrowman NJ. A systematic review identifies a lack of standardization in methods for handling missing variance data. Journal of Clinical Epidemiology 2006;59(4):342-53.

\section{Zoons 2012}

Zoons E, Dijkgraaf MG, Dijk JM, van Schaik IN, Tijssen MA. Botulinum toxin as treatment for focal dystonia: a systematic review of the pharmaco-therapeutic and pharmaco-economic value. Neurology 2012;259(12):2519-26.

\section{References to other published versions of this review Costa 2003}

Costa J, Borges AA, Espírito-Santo CC, Ferreira J, Coelho MM, Moore P, Sampaio C. Botulinum toxin type A versus botulinum toxin type B for cervical dystonia. Cochrane Database of Systematic Reviews 2003, Issue 3. [DOI: 10.1002/14651858.CD004314.pub2] 


\section{CHARACTERISTICS OF STUDIES}

Characteristics of included studies [ordered by study ID]

Comella 2005

Methods Randomised, double-blind, controlled study; randomisation in permuted block allocation schemes.

Data were collected at baseline, week 4, and every 2 weeks thereafter up to 20 weeks post-injection.

Data were analysed on a ITT basis.

Participants

The study was conducted in the outpatient offices of unspecified dystonia study centres.

139 randomised participants

Mean age of participants was 56.7 years; $68 \%$ were female; the combined duration of cervical dystonia was 7.9 years. The mean TWSTRS total score was 41.8 .

All participants had previously been exposed to a form of botulinum neurotoxin, and were required to have moderate severity $C D$, as well as a minimum of 15 on the TWSTRS motor severity subsection, for inclusion.

Exclusion criteria: predominant anterocollis and retrocollis

Interventions

139 participants were randomised into 2 groups: BtA group $(n=74)$; BtB group $(n=65)$

BtA group: BtA was obtained in vials containing $100 \mathrm{U}$ Clostridium botulinum toxin type A, $0.5 \mathrm{mg}$ albumin (human), and $0.9 \mathrm{mg}$ sodium chloride in a sterile vacuum-dried form without a preservative. BtA was stored at a temperature at or below $-5^{\circ} \mathrm{C}$ and reconstituted within $4 \mathrm{~h}$ of administration with $1 \mathrm{~mL}$ of $0.9 \%$ sterile unpreserved saline to provide a final concentration of $100 \mathrm{U} / \mathrm{mL}$. Subjects randomised to $\mathrm{BtA}$ received a maximal dose of $250 \mathrm{U}(2.5 \mathrm{~mL})$. Subjects were injected with a volume of the appropriate study drug based on previous injection amounts. Muscle selection, dosing into each muscle, number of injection sites, and use of electromyography were at the discretion of the injecting physician.

BtB group: BtB was obtained in vials containing at least $5000 \mathrm{U}$ Clostridium botulinum toxin type B, $0.05 \%$ albumin (human), $0.01 \mathrm{M}$ sodium succinate, and $0.1 \mathrm{M}$ sodium chloride buffer at a $\mathrm{pH}$ of 5.6. Commercially available vials of BtB contain overfill of approximately $0.1 \mathrm{~mL}$ to $0.2 \mathrm{~mL}$ or $500 \mathrm{U}$ to 1000 $\mathrm{U} B \mathrm{BtB}$. The BtB was stored at a temperature between $2^{\circ} \mathrm{C}$ and $8^{\circ} \mathrm{C}$. Each vial of $\mathrm{BtB}$ was diluted with 0.25 $\mathrm{mL}$ of $0.9 \%$ sterile unpreserved saline to provide a concentration of at least $4000 \mathrm{U} / \mathrm{mL}$. Subjects randomised to BtB received a maximal dose of $10,000 \mathrm{U}(2.5 \mathrm{~mL})$.

\section{Primary outcomes:}

- Change in total TWSTRS score at week 4

- Duration of clinical effect (the time in days until the target TWSTRS score was reached)

- Adverse effects evaluated by spontaneous report and adverse events interviews

\section{Secondary outcomes:}

- Physician Global Assessment of Change ( -4 is very marked worsening, 0 is no change and +4 is complete remission)

- Patient Global Assessment and pain and discomfort at baseline injection

No neutralising antibody testing was performed.

Notes

\section{Risk of bias}


Comella 2005 (Continued)

\section{Bias Authors' judgement Support for judgement}

Random sequence genera- Low risk tion (selection bias)
Quote: "Random assignments were generated by the study biostatistician, were stratified by center, and used permuted block allocation schemes with blocks of randomly allocated lengths of two or four. The study biostatistician ensured that the initial assignments were balanced across centers. The permuted block approach prevented imbalances in the numbers randomized to each treatment arm..."

Allocation concealment Low risk
(selection bias)

(selection bias)
Quote: "Random assignments were generated by the study biostatistician, were stratified by center, and used permuted block allocation schemes with blocks of randomly allocated lengths of two or four. The study biostatistician ensured that the initial assignments were balanced across centers. The permuted block approach prevented imbalances in the numbers randomized to each treatment arm..."

\begin{tabular}{|c|c|c|}
\hline $\begin{array}{l}\text { Blinding of participants } \\
\text { and personnel (perfor- } \\
\text { mance bias) } \\
\text { Outcome group: Principal } \\
\text { Investigator (PI) }\end{array}$ & Unclear risk & $\begin{array}{l}\text { Quote: "The principal/treating investigator (PI) enrolled the subjects, assessed } \\
\text { the inclusion and exclusion criteria, obtained informed consent, applied and } \\
\text { evaluated the UBI [unilateral brow injection], performed the injection of study } \\
\text { drug (BoNTA or BoNTB), reported complications associated with injection, } \\
\text { assessed adverse events, and determined when subjects reached the de- } \\
\text { fined end point of the study. (...) The PI, RI, and coordinator were blinded to } \\
\text { serotype administered to each subject." }\end{array}$ \\
\hline
\end{tabular}

\begin{tabular}{|c|c|c|}
\hline $\begin{array}{l}\text { Blinding of participants } \\
\text { and personnel (perfor- } \\
\text { mance bias) } \\
\text { Outcome group: Rating } \\
\text { Investigator (RI) }\end{array}$ & Low risk & $\begin{array}{l}\text { Quote: "The rating investigator (RI) reviewed the TWSTRS teaching tape to en- } \\
\text { sure uniform ratings and assessed subjects using the TWSTRS (motor sever- } \\
\text { ity, disability, and pain) and the physician's global assessment (PGA). The RI } \\
\text { did not perform other study procedures. (...) The PI, RI, and coordinator were } \\
\text { blinded to serotype administered to each subject." }\end{array}$ \\
\hline
\end{tabular}

\begin{tabular}{ll}
\hline $\begin{array}{l}\text { Blinding of participants } \\
\text { and personnel (perfor- }\end{array}$ & Low risk \\
$\begin{array}{l}\text { mance bias) } \\
\begin{array}{l}\text { Outcome group: Study } \\
\text { Coordinator }\end{array}\end{array}$ & $\begin{array}{l}\text { medications, obtained the subjective global assessment (SGA), and completed } \\
\text { study-related questionnaires. (...) The PI, Rl, and coordinator were blinded to } \\
\text { serotype administered to each subject." }\end{array}$ \\
\end{tabular}

\begin{tabular}{|c|c|c|}
\hline $\begin{array}{l}\text { Blinding of participants } \\
\text { and personnel (perfor- } \\
\text { mance bias) } \\
\text { Outcome group:Indepen- } \\
\text { dent Drug Preparer }\end{array}$ & Low risk & $\begin{array}{l}\text { Quote: "The drug preparer obtained the randomization code for each subject } \\
\text { from the study biostatistician and prepared the BoNTA or BoNTB." } \\
\text { The drug preparer was not involved in other study procedures. }\end{array}$ \\
\hline $\begin{array}{l}\text { Blinding of outcome as- } \\
\text { sessment (detection bias) } \\
\text { Outcome group: Objective } \\
\text { Outcomes }\end{array}$ & Low risk & $\begin{array}{l}\text { Quote: "The PI, RI, and coordinator were blinded to serotype administered to } \\
\text { each subject." }\end{array}$ \\
\hline $\begin{array}{l}\text { Blinding of outcome as- } \\
\text { sessment (detection bias) } \\
\text { Outcome group: Subjec- } \\
\text { tive Outcomes }\end{array}$ & Low risk & $\begin{array}{l}\text { All participants had previous successful treatment with BtA, which could have } \\
\text { led to the recognition of the expected effect, or to the lack of it. However, this } \\
\text { would presumably not have an effect as the comparison arm was also a botu- } \\
\text { linum toxin formulation. }\end{array}$ \\
\hline $\begin{array}{l}\text { Incomplete outcome data } \\
\text { (attrition bias) } \\
\text { All outcomes }\end{array}$ & Low risk & $\begin{array}{l}\text { Only one post-randomisation withdrawal occurred, in the BtA group (inability } \\
\text { to travel to the study site). } \\
\text { The ITT analysis of the primary outcome variables for the TWSTRS and adverse } \\
\text { events was done for all participants examined at week } 4 \text {. }\end{array}$ \\
\hline
\end{tabular}


Comella 2005 (Continued)

Selective reporting (re- Low risk The expected outcomes that are usually evaluated in intervention trials for porting bias) this condition were reported in this study.

For-profit bias

High risk

Quote: "Supported primarily by an unrestricted research grant from Allergan Inc., Irvine, CA."

\section{Enriched population - ex- High risk} clusive enrolment of positive responders
Quote: "All subjects were followed up in outpatient clinics and had previous successful treatment with BoNTA, with a subjective report of at least $30 \%$ benefit."

Quote: "At the baseline visit, the PI evaluated the UBI [unilateral brow injection], and excluded subjects with UBI indicating clinical resistance (no effacement of brow wrinkling). Subjects were then randomized to either BoNTA or BoNTB"

\begin{tabular}{|c|c|c|}
\hline $\begin{array}{l}\text { Enriched population - ex- } \\
\text { clusion of poor responders }\end{array}$ & Unclear risk & $\begin{array}{l}\text { Quote: "Subjects were also excluded if they had predominant anterocollis or } \\
\text { retrocollis" }\end{array}$ \\
\hline
\end{tabular}

\section{Pappert 2008}

\section{Methods}

Randomised, double-blind, controlled trial; randomisation was done via a Interactive Voice Response system, which created a subject randomisation number which was then forwarded to the site pharmacist who prepared the study drug.

Data were collected at baseline, week 4 post-injection and every 4 weeks until there was a further need for botulinum therapy.

Both PP and ITT analyses were performed, but the study reported only the PP analysis.

\section{Participants}

Multi-centre trial conducted in 24 sites in Europe (Poland, Hungary, UK, Italy, Spain, Germany, Slovakia, France and Portugal).

111 randomised participants

Mean age $=48.9$ years; $55.9 \%$ were female; and the average duration of CD was 6.6 years.

Exclusion criteria: people with pure anterocollis and retrocollis, as well as previous treatment with botulinum toxin

Interventions

Participants were randomised into 2 groups: BtA group $(n=56)$; BtB group $(n=55)$

BtA group: BtA was obtained by the pharmacy (100 U of vacuum-dried BtA neurotoxin complex) and stored at or below $-5^{\circ} \mathrm{C}$. The final concentration of BtA was $75 \mathrm{U} / \mathrm{mL}$. Electromyography was used at the discretion of the investigator providing the injection.

BtB group: BtB supplied by the manufacturer in insulated shipping boxes, and maintained at $2^{\circ} \mathrm{C}$ to $8^{\circ} \mathrm{C}$. $\mathrm{BtB}$ is a clear, colourless to light yellow, sterile injectable solution containing $5000 \mathrm{U}$ of BtB per $\mathrm{mL}$ in an isotonic solution of $0.05 \%$ human serum albumin $/ 0.01 \mathrm{M}$ succinate $/ 0.1 \mathrm{M}$ sodium chloride buffer at an approximate $\mathrm{pH}$ of 5.6. The final concentration of $\mathrm{BtB}$ was $5,000 \mathrm{U} / \mathrm{mL}$. Electromyography was used at the discretion of the investigator providing the injection.

\section{Outcomes}

\section{Primary outcome:}

- Change in total TWSTRS score at 4 weeks post-injection

\section{Secondary outcomes:}

- Change in TWSTRS sub-scores (i.e. pain, severity and disability)

- Subject pain assessment on VAS 
- Primary Investigator and Patient Global Assessment (5-point scales for both frequency and intensity) on VAS at week 4

- Adverse events by spontaneous reporting and on investigation

No neutralising antibody testing was performed.

Notes

\section{Risk of bias}

Bias Authors' judgement Support for judgement

Random sequence genera- Unclear risk tion (selection bias)

Quote: "Subjects were randomized in a 1:1 ratio of BoNT-A [BtA] to BoNT-B $[\mathrm{BtB}]$. The site Principal Investigator (PI) contacted an Interactive Voice Response system for a Subject Randomization Number."

\begin{tabular}{|c|c|c|}
\hline $\begin{array}{l}\text { Allocation concealment } \\
\text { (selection bias) }\end{array}$ & Low risk & $\begin{array}{l}\text { Quote: "Treatment allocation for the randomization number was forwarded to } \\
\text { the site pharmacist who prepared the study drug and had no contact with the } \\
\text { subject or injector. All other study personnel were blinded." }\end{array}$ \\
\hline
\end{tabular}

Blinding of participants Low risk and personnel (performance bias)

Outcome group: Principal Investigator (PI)
Quote: "At screening ( $\leq 21$ days prior to baseline visit), the PI performed a history, examination, and confirmed inclusion/exclusion criteria. At baseline, prior to injection, the PI performed the TWSTRS (...). At week 4 and all subsequent visits, the PI performed the TWSTRS and Investigator Global VAS $0 \mathrm{~mm}$ (much worse) to $100 \mathrm{~mm}$ (much better) at the time of evaluation compared to baseline]."

Quote: "All other study personnel were blinded"

Blinding of participants Low risk and personnel (performance bias)

Outcome group: Rating Investigator (RI)

Quote: "At baseline, prior to injection, (...) the Al administered the subject Pain Visual Analogue Scale (VAS) [0 mm (worst pain ever) to $100 \mathrm{~mm}$ (no pain)].

The Administrative Investigator conducted the remaining visits including collection of AEs and the administration of the Subject Pain VAS and Subject Global VAS [ranging from $0 \mathrm{~mm}$ (much worse) to $100 \mathrm{~mm}$ (much better) at the time of evaluation compared to baseline]."

Quote: "All other study personnel were blinded"

Blinding of participants Low risk
and personnel (perforQuote: "At baseline, prior to injection, (...) the Al administered the subject Pain Visual Analogue Scale (VAS) [0 mm (worst pain ever) to $100 \mathrm{~mm}$ (no pain)].

mance bias)

Outcome group: Study

Coordinator
The Administrative Investigator conducted the remaining visits including collection of AEs and the administration of the Subject Pain VAS and Subject Global VAS [ranging from $0 \mathrm{~mm}$ (much worse) to $100 \mathrm{~mm}$ (much better) at the time of evaluation compared to baseline]."

Quote: "All other study personnel were blinded"

$\begin{array}{ll}\begin{array}{l}\text { Blinding of participants } \\ \text { and personnel (perfor- }\end{array} & \text { Low risk } \\ \begin{array}{l}\text { mance bias) } \\ \text { Outcome group:Indepen- } \\ \text { dent Drug Preparer }\end{array} & \begin{array}{l}\text { Quote: "pharmacist who prepared the study drug and had no contact with the } \\ \text { subject or injector". }\end{array}\end{array}$

Blinding of outcome as- Low risk Quote: "All other study personnel were blinded."
sessment (detection bias)
Outcome group: Objective
Outcomes


Pappert 2008 (Continued)

Blinding of outcome as- Low risk All participants were toxin-naive. However, this would presumably not have an sessment (detection bias)

Outcome group: Subjective Outcomes

\section{Incomplete outcome data Unclear risk} (attrition bias)

All outcomes Postrandomisation exclusions were low and roughly distributed evenly be-
tween groups (BtA group $=8$; BtB group $=10)$.

The reasons for exclusion were presented. Five of the exclusions in the BtB group, and all of them (8) in the BtB group, were due to ;protocol violations', which were not specified. However, the authors describe that "all 13 subjects that were excluded for protocol violations in the PP population were from one site where the study personnel had not been appropriately trained."

The data reported included only those according to the PP principle, despite the authors claiming that there were no differences between PP and ITT.

\begin{tabular}{|c|c|c|}
\hline $\begin{array}{l}\text { Selective reporting (re- } \\
\text { porting bias) }\end{array}$ & Low risk & $\begin{array}{l}\text { The expected outcomes that are usually evaluated in intervention trials for } \\
\text { this condition were reported in this study. }\end{array}$ \\
\hline
\end{tabular}

\begin{tabular}{ll}
\hline For-profit bias & High risk \\
& $\begin{array}{l}\text { Quote: “Eric J. Pappert, MD and Terry Germanson, PhD for The Myobloc/Neu- } \\
\text { robloc European Cervical Dystonia Study Group" }\end{array}$ \\
& $\begin{array}{l}\text { Quote: “The first named author (EJP) is an employee of Solstice Neuro- } \\
\text { sciences, Inc. maker of MYOBLOC }\end{array}$ (BoNT-B) and took charge of the publica- \\
tion and analysis after the study was completed. (...) The statistical consultant \\
(TG) is an independent contractor paid for her analytic time by Solstice Neuro- \\
sciences, Inc. and has nothing further to disclose."
\end{tabular}

Enriched population - ex- Low risk Quote: “Exclusion criteria included: (...) previous treatment with BoNT"
clusive enrolment of positive responders

Methods Randomised, double-blind, controlled trial; randomisation method not explained.

Data were collected at baseline and at week 2 post-injection.

It is unclear wether the data were analysed PP or by an ITT method.

The location of the study was not mentioned.
$\begin{aligned} & 20 \text { randomised participants } \\ & \text { Mean age: BtA group = } 55 \text { years; BtB group = } 64 \text { years; } 14 \text { participants were female. The duration of CD } \\ & \text { in the participants is unknown. } \\ & \text { Participants were required to have a previous response to BtA within the last year of sufficient magni- } \\ & \text { tude for functional improvement. }\end{aligned}$

$\begin{array}{ll}\text { Interventions } & \text { BtA group: } \mathrm{n}=11 \\ & \text { BtB group: } \mathrm{n}=9\end{array}$


Tintner 2005 (Continued)

No information was provided about the specific dosages or frequency of administration of Bt therapy.

No information was provided about length of follow-up.

\section{Outcomes}

\section{Primary outcome:}

- TWSTRS sub-score at week 2 post-injection

\section{Secondary outcomes:}

- Heart rate

- Blood pressure

- Orthostatic heart rate regulation

- Heart rate variation with respiration

- Saliva production

- Ocular autonomic testing

- Composite Autonomic Scoring Scale

- Visual Functional Questionnaire

Notes

\section{Risk of bias}

\begin{tabular}{|c|c|c|}
\hline Bias & Authors' judgement & Support for judgement \\
\hline $\begin{array}{l}\text { Random sequence genera- } \\
\text { tion (selection bias) }\end{array}$ & Unclear risk & $\begin{array}{l}\text { The text refers to this trial being randomised, though method of randomisa- } \\
\text { tion was not specified. }\end{array}$ \\
\hline $\begin{array}{l}\text { Allocation concealment } \\
\text { (selection bias) }\end{array}$ & Unclear risk & Method of allocation concealment not specified. \\
\hline $\begin{array}{l}\text { Blinding of participants } \\
\text { and personnel (perfor- } \\
\text { mance bias) } \\
\text { Outcome group: Principal } \\
\text { Investigator (PI) }\end{array}$ & Unclear risk & $\begin{array}{l}\text { The text refers to this trial being double-blind, though no evidence of adequate } \\
\text { participant blinding was provided. }\end{array}$ \\
\hline
\end{tabular}

\begin{tabular}{|c|c|c|}
\hline $\begin{array}{l}\text { Blinding of participants } \\
\text { and personnel (perfor- }\end{array}$ & Unclear risk & $\begin{array}{l}\text { The text refers to this trial being double-blind, though no evidence of adequate } \\
\text { participant blinding was provided. }\end{array}$ \\
\hline
\end{tabular}
mance bias)

Outcome group: Rating

Investigator (RI)

Blinding of participants Unclear risk
and personnel (perfor-
mance bias)
Outcome group: Study
Coordinator
The text refers to this trial being double-blind, though no evidence of adequate participant blinding was provided.

Blinding of participants
and personnel (perfor-
mance bias)
Outcome group:Indepen-
dent Drug Preparer

Blinding of outcome as-

sessment (detection bias)

Outcome group: Objective

Outcomes
Unclear risk

The text refers to this trial being double-blind, though no evidence of adequate participant blinding was provided. 
Tintner 2005 (Continued)

Blinding of outcome as- Unclear risk The text refers to this trial being double-blind, though no evidence of adequate sessment (detection bias)

Outcome group: Subjec-

tive Outcomes

\begin{tabular}{|c|c|c|}
\hline $\begin{array}{l}\text { Incomplete outcome data } \\
\text { (attrition bias) }\end{array}$ & Low risk & $\begin{array}{l}\text { Quote: "20 subjects with cervical dystonia responsive to BTX-A were random- } \\
\text { ized and completed the study" }\end{array}$ \\
\hline
\end{tabular}

All outcomes Selective reporting (re- High risk
porting bias)
Quote: "20 subjects with cervical dystonia responsive to BTX-A were randomAlthough the report refers, in the methods section, to having selected several outcomes, only 2 of these were reported in the results. Moreover, due to inherent BtA properties the outcome assessment usually lasted at least until the week 16 after the treatment section.

\begin{tabular}{lll}
\hline For-profit bias & High risk & $\begin{array}{l}\text { Trial report refers to this study having been supported by a grant from Allergan } \\
\text { Inc. }\end{array}$ \\
\hline $\begin{array}{l}\text { Enriched population - ex- } \\
\begin{array}{l}\text { clusive enrolment of posi- } \\
\text { tive responders }\end{array}\end{array}$ & High risk & $\begin{array}{l}\text { Subjects were required to be known responders to the effects of BTA within } \\
\text { the past year. }\end{array}$ \\
\hline $\begin{array}{l}\text { Enriched population - ex- } \\
\text { clusion of poor responders }\end{array}$ & Low risk & No reference made to exclusion of poor responders. \\
\hline
\end{tabular}

\author{
Abbreviations \\ Al: assistant investigator \\ AEs: adverse events \\ Bt: botulinum toxin \\ BtA: botulinum toxin type $A$ (onabotulinumtoximA only in this systematic review) \\ BtB: botulinum toxin type $B$ (rimabotulinumtoxinB) \\ CD: cervical dystonia \\ h: hour(s) \\ ITT: intention-to-treat analysis \\ PI: principal investigator \\ PP: per protocol \\ TWSTRS: Toronto Western Spasmodic Torticollis Rating Scale
}

\title{
DATA AND ANALYSES
}

\section{Comparison 1. Botulinum toxin type A versus botulinum toxin type $B$}

\begin{tabular}{lllll}
\hline Outcome or subgroup title & No. of studies & $\begin{array}{l}\text { No. of partici- } \\
\text { pants }\end{array}$ & Statistical method & Effect size \\
\hline $\begin{array}{l}1 \text { Overall cervical dystonia improvement } \\
\text { as assessed with validated scales: change } \\
\text { from baseline to week 4 }\end{array}$ & 2 & 231 & $\begin{array}{l}\text { Mean Difference (IV, Ran- } \\
\text { dom, 95\% Cl) }\end{array}$ & $-1.44[-3.58,0.70]$ \\
\hline $\begin{array}{l}2 \text { Cervical dystonia associated severity: } \\
\text { change from baseline to week 2-4 as as- } \\
\text { sessed with validated scales }\end{array}$ & 3 & 251 & Mean Difference (IV, Ran- & $-0.26[-1.27,0.75]$ \\
\hline $\begin{array}{l}3 \text { Cervical dystonia associated disability: } \\
\text { change from baseline to week 2-4 as as- } \\
\text { sessed with validated scales }\end{array}$ & 3 & $251)$ & Mean Difference (IV, Ran- & $-0.17[-1.19,0.86]$ \\
\hline \hline
\end{tabular}




\begin{tabular}{|c|c|c|c|c|}
\hline Outcome or subgroup title & No. of studies & $\begin{array}{l}\text { No. of partici- } \\
\text { pants }\end{array}$ & Statistical method & Effect size \\
\hline $\begin{array}{l}4 \text { Proportion of participants with adverse } \\
\text { events }\end{array}$ & 1 & 111 & $\begin{array}{l}\text { Risk Ratio (M-H, Random, } \\
95 \% \mathrm{Cl} \text { ) }\end{array}$ & $1.40[1.00,1.96]$ \\
\hline $\begin{array}{l}5 \text { Subjective change as assessed by the pa- } \\
\text { tient at week } 4\end{array}$ & 1 & 138 & $\begin{array}{l}\text { Mean Difference (IV, Ran- } \\
\text { dom, } 95 \% \mathrm{CI} \text { ) }\end{array}$ & $0.20[-0.17,0.57]$ \\
\hline $\begin{array}{l}6 \text { Subjective change as assessed by clini- } \\
\text { cian at week } 4\end{array}$ & 1 & 138 & $\begin{array}{l}\text { Mean Difference (IV, Ran- } \\
\text { dom, } 95 \% \mathrm{CI} \text { ) }\end{array}$ & $0.20[-0.20,0.60]$ \\
\hline $\begin{array}{l}7 \text { Cervical dystonia associated pain: } \\
\text { change from baseline to week } 2-4 \text { as as- } \\
\text { sessed with validated scales }\end{array}$ & 3 & 251 & $\begin{array}{l}\text { Mean Difference (IV, Ran- } \\
\text { dom, } 95 \% \mathrm{CI} \text { ) }\end{array}$ & $-0.83[-1.75,0.09]$ \\
\hline 8 Adverse event: sore throat/dry mouth & 2 & 212 & $\begin{array}{l}\text { Risk Ratio (M-H, Random, } \\
95 \% \mathrm{Cl} \text { ) }\end{array}$ & $4.39[2.43,7.91]$ \\
\hline 9 Adverse event: dysphagia & 3 & 249 & $\begin{array}{l}\text { Risk Ratio (M-H, Random, } \\
95 \% \mathrm{Cl} \text { ) }\end{array}$ & $2.89[0.80,10.41]$ \\
\hline 10 Adverse event: injection site pain & 1 & 111 & $\begin{array}{l}\text { Risk Ratio (M-H, Random, } \\
95 \% \mathrm{Cl} \text { ) }\end{array}$ & $0.14[0.01,2.66]$ \\
\hline
\end{tabular}

Analysis 1.1. Comparison 1 Botulinum toxin type A versus botulinum toxin type B, Outcome 1 Overall cervical dystonia improvement as assessed with validated scales: change from baseline to week 4.

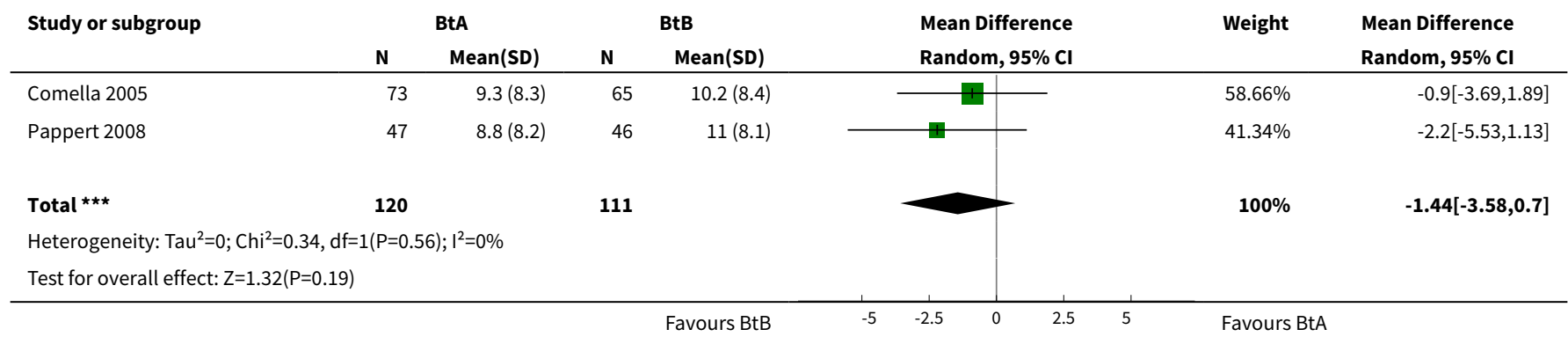

\section{Analysis 1.2. Comparison 1 Botulinum toxin type $A$ versus botulinum toxin type $B$, Outcome 2 Cervical dystonia associated severity: change from baseline to week 2-4 as assessed with validated scales.}

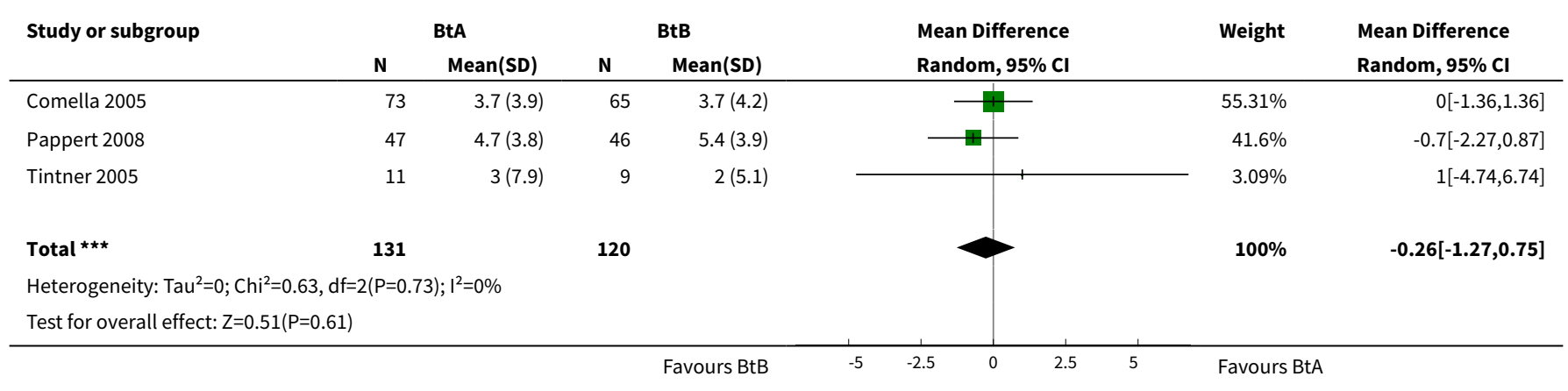




\section{Analysis 1.3. Comparison 1 Botulinum toxin type A versus botulinum toxin type B, Outcome 3 Cervical dystonia associated disability: change from baseline to week 2-4 as assessed with validated scales.}

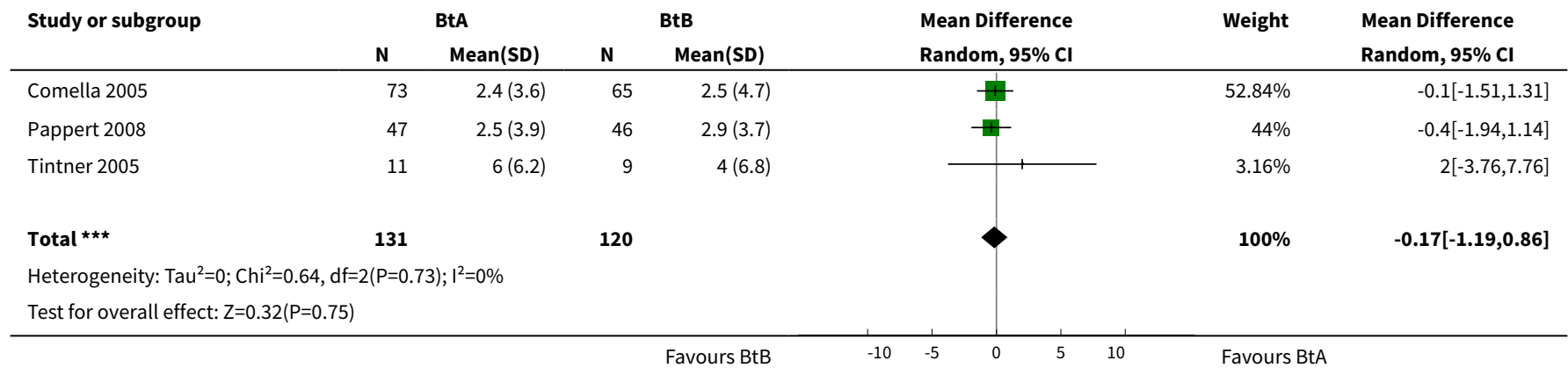

Analysis 1.4. Comparison 1 Botulinum toxin type $A$ versus botulinum toxin type B, Outcome 4 Proportion of participants with adverse events.

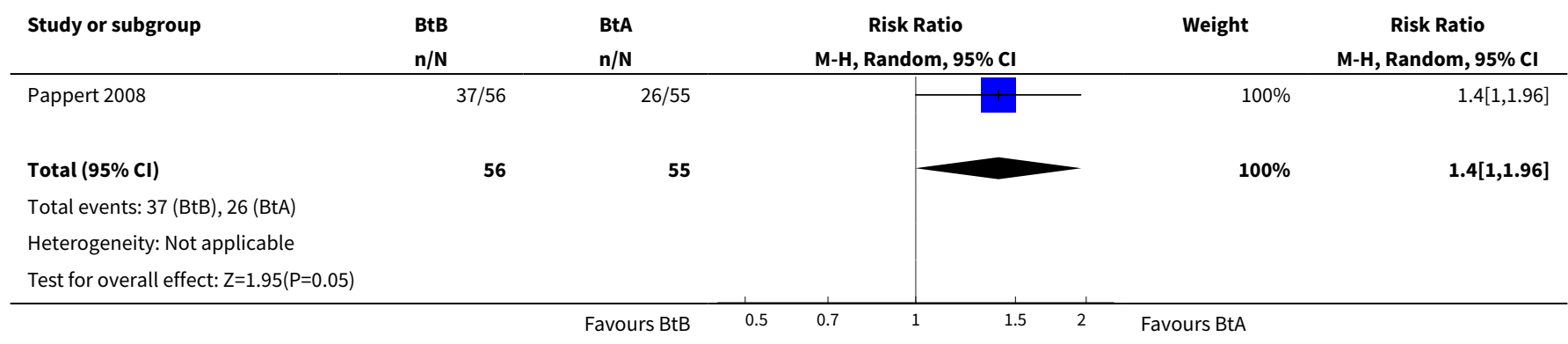

Analysis 1.5. Comparison 1 Botulinum toxin type $A$ versus botulinum toxin type B, Outcome 5 Subjective change as assessed by the patient at week 4 .

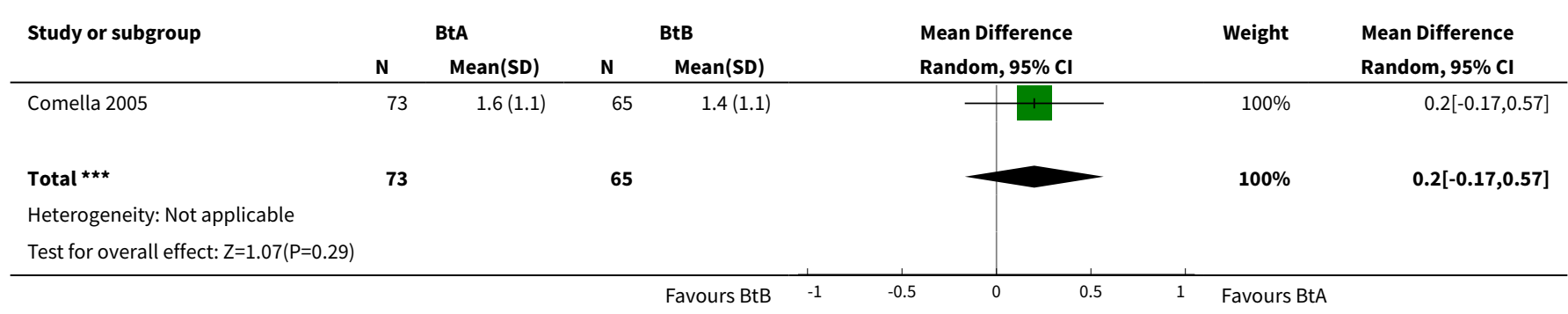

Analysis 1.6. Comparison 1 Botulinum toxin type $A$ versus botulinum toxin type B, Outcome 6 Subjective change as assessed by clinician at week 4.

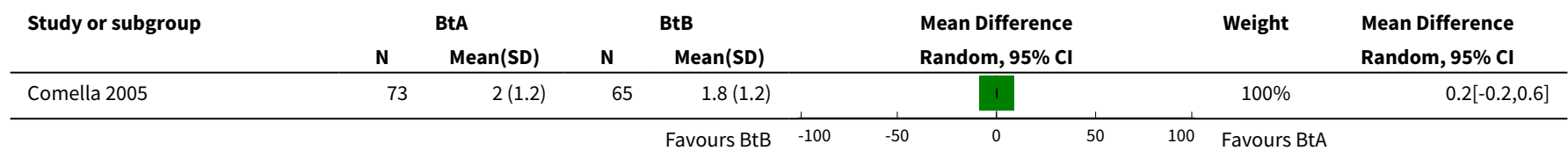




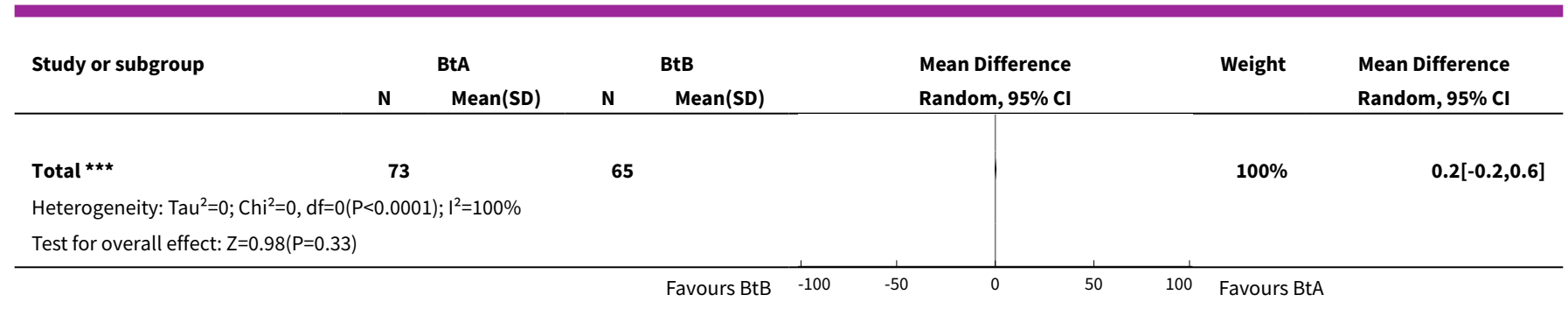

Analysis 1.7. Comparison 1 Botulinum toxin type A versus botulinum toxin type B, Outcome 7 Cervical dystonia associated pain: change from baseline to week 2-4 as assessed with validated scales.

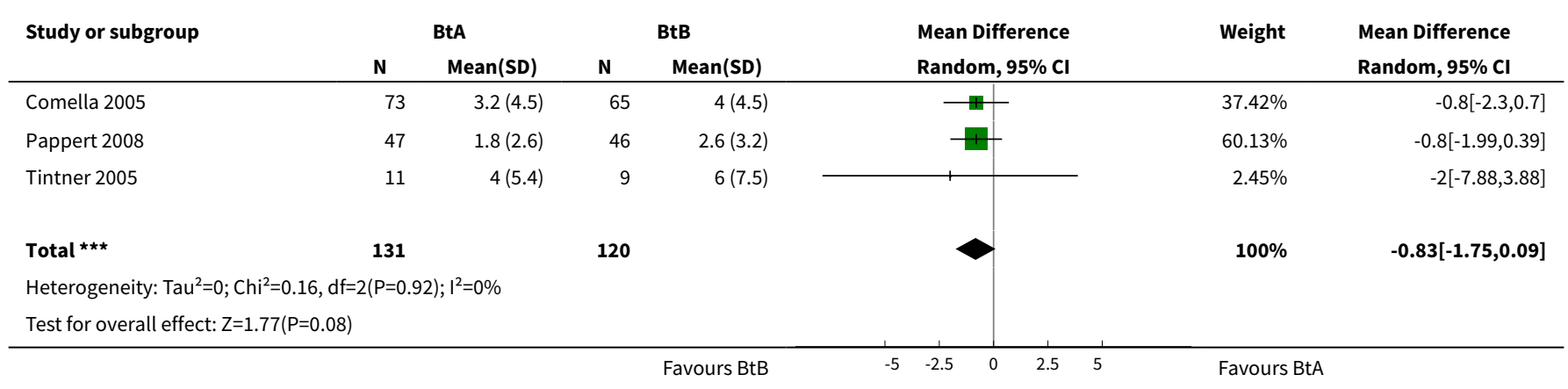

Analysis 1.8. Comparison 1 Botulinum toxin type $A$ versus botulinum toxin type B, Outcome 8 Adverse event: sore throat/dry mouth.

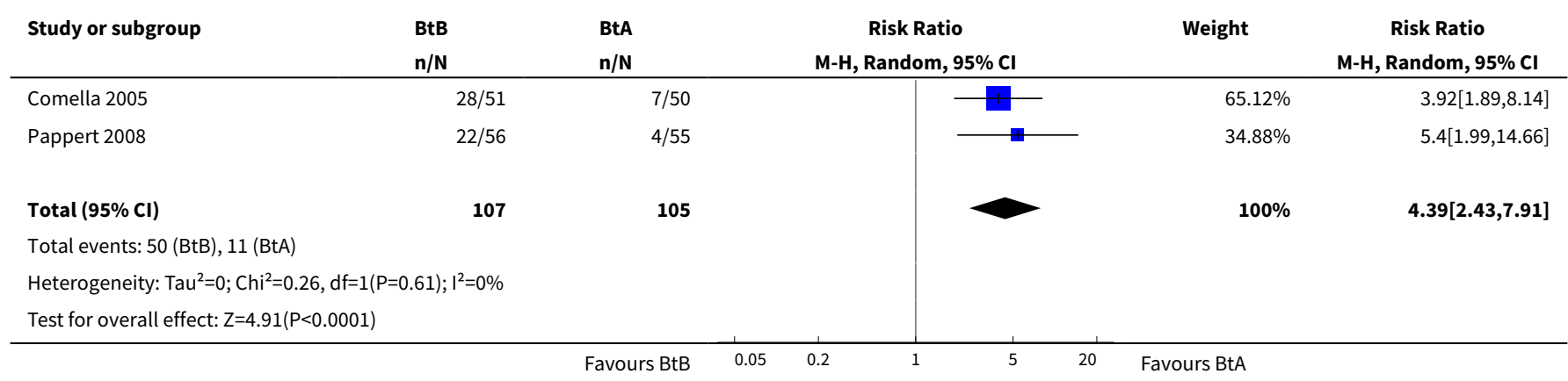

Analysis 1.9. Comparison 1 Botulinum toxin type $A$ versus botulinum toxin type B, Outcome 9 Adverse event: dysphagia.

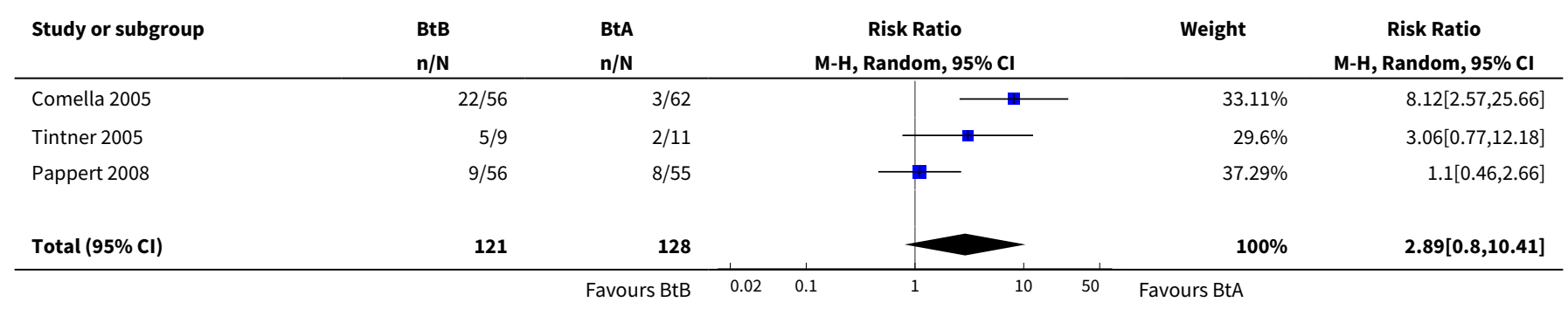




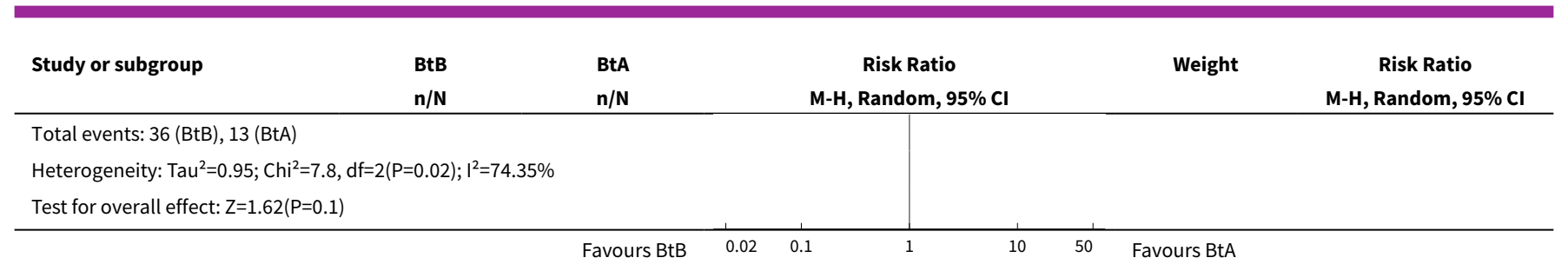

Analysis 1.10. Comparison 1 Botulinum toxin type $A$ versus botulinum toxin type B, Outcome 10 Adverse event: injection site pain.

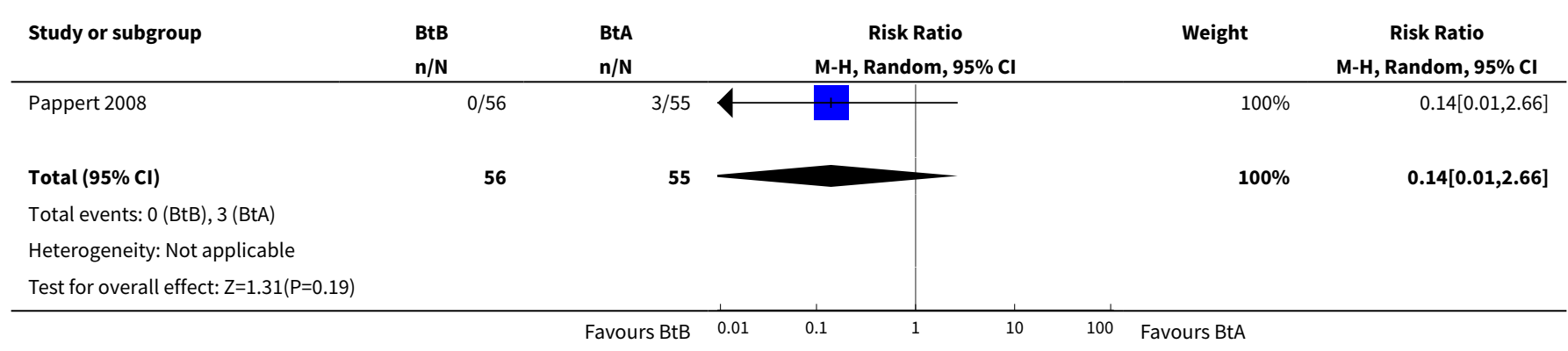

\section{ADDITIONAL TABLES}

Table 1. Glossary of terms

\begin{tabular}{ll}
\hline Term & Definition \\
\hline BtA-non-responsive & People who do not experience the expected benefit from treatment with botulinum toxin type A \\
\hline $\begin{array}{l}\text { Cervical dystonia or spas- } \\
\text { modic torticollis }\end{array}$ & $\begin{array}{l}\text { A common movement disorder in which people have abnormal movements or postures of the head } \\
\text { and neck that they cannot control. It is frequently accompanied by social embarrassment and pain. }\end{array}$ \\
\hline Chemodenervation & $\begin{array}{l}\text { The process by which botulinum toxin causes muscular paralysis. Although all the anatomical ele- } \\
\text { ments necessary for muscular control are intact (i.e. nerve, synapse and muscle), there is a chemi- } \\
\text { cal process that disables the transmission of the electrical signal from the nerve to the muscle. }\end{array}$ \\
\hline Dysphagia & Discomfort or difficulty when swallowing \\
\hline Electromyography & $\begin{array}{l}\text { An examination that displays the electrical activity of muscles using pieces of metal attached to the } \\
\text { skin or inserted into the muscle }\end{array}$ \\
\hline Non-naive & People who have been treated in the past with botulinum toxin \\
\hline Voluntary action & Movements that are normally under a person's control, that can be started and stopped at will \\
\hline
\end{tabular}

Table 2. Percentage of BtB-treated participants with adverse events of special interest: Comella 2005 versus Marques 2016 versus current review

\begin{tabular}{llll}
\hline Adverse event of special interest & Comella 2005 & Marques 2016 & Current review \\
\hline
\end{tabular}


Table 2. Percentage of BtB-treated participants with adverse events of special interest: Comella 2005 versus Marques 2016 versus current review (Continued)

\begin{tabular}{llll} 
Sore throat/dry mouth & $48 \%$ & $17 \%$ & $47 \%$ \\
\hline Dysphagia & $80 \%$ & $16 \%$ & $29 \%$ \\
\hline
\end{tabular}

Marques 2016 is a Cochrane systematic review that studied efficacy and safety of BtB compared to placebo

\section{A P P E N D I CES}

\section{Appendix 1. CENTRAL search strategy}

\#1 MeSH descriptor: [Botulinum Toxins] explode all trees

\#2 Botulinum Toxins, Type A

\#3 (botul* near/2 tox*):ti,ab

\#4 (botox or dysport or xeomin or myobloc or rimabotulinum ${ }^{\star}$ or abobotuli* or onabotulinum ${ }^{\star}$ or oculinum or purtox or CNBTX or Neuronox):ti,ab

\#5 $\{$ or \#1-\#4\}

\#6 MeSH descriptor: [Dystonic Disorders] explode all trees

\#7 MeSH descriptor: [Dystonia] explode all trees

\#8 MeSH descriptor: [Torticollis] explode all trees

\#9 MeSH descriptor: [Blepharospasm] explode all trees

\#10 MeSH descriptor: [Meige Syndrome] explode all trees

\#11 MeSH descriptor: [Hemifacial Spasm] explode all trees

\#12 (cervic* near/2 dysto*):ti,ab

\#13 blepharosp*:ti,ab

\#14 (hem near/2 spasm*):ti,ab

\#15 (meige and (dysto* or syndrom $\left.\left.{ }^{\star}\right)\right): t i, a b$

\#16 (crani* near/2 dysto*):ti,ab

\#17 (foca* near/2 dysto*):ti,ab

\#18 (write* and (cramp* or dysto*)):ti,ab

\#19 torticol*:ti,ab

\#20 \{or \#6-\#19\}

$\# 21 \# 5$ and \#20

\#22 MeSH descriptor: [Animals] explode all trees

\#23 MeSH descriptor: [Humans] explode all trees

\#24 \#22 not \#23

\#25 \#21 not \#24 in Trials 


\section{Appendix 2. MEDLINE search strategy}

\#1 randomized controlled trial.pt.

\#2 controlled clinical trial.pt.

\#3 randomized.ab.

\#4 placebo.ab.

\#5 clinical trials as topic.sh.

\#6 randomly.ab.

\#7 trial.ti.

\#8 1 or 2 or 3 or 4 or 5 or 6 or 7

\#9 exp botulinum toxins/

\#10 exp botulinum toxins, type $\mathrm{A} /$

\#11 (botul\$ adj2 tox\$).ti,ab.

\#12 (botox or dysport or xeomin or myobloc or rimabotulinum\$ or abobotuli\$ or onabotulinum\$ or oculinum or purtox or CNBTX or Neuronox).ti,ab.

\#13 9 or 10 or 11 or 12

\#14 (cervic\$ adj2 dysto\$).ti,ab.

\#15 blepharosp\$.ti,ab.

\#16 (hem\$ adj2 spasm\$).ti,ab.

$\# 17$ (meige and (dysto\$ or syndrom\$)).ti,ab.

\#18 (crani\$ adj2 dysto\$).ti,ab.

\#19 (foca\$ adj2 dysto\$).ti,ab.

\#20 (write\$ and (cramp\$ or dysto\$)).ti,ab.

\#21 torticol\$s.ti,ab.

\#22 exp dystonic disorders/

\#23 exp dystonia/

\#24 exp torticollis/

\#25 exp blepharospasm/

\#26 exp meige syndrome/

\#27 exp hemifacial spasm/

\#28 14 or 15 or 16 or 17 or 18 or 19 or 20 or 21 or 22 or 23 or 24 or 25 or 26 or 27

\#29 8 and 3 and 28

\#30 exp animals/ not humans/

\#31 29 not 30

\section{Appendix 3. Embase search strategy}

$\# 1$ random\$.tw. 
\#2 clinical trial:.mp.

\#3 placebo\$.mp.

\#4 double-blind\$.tw.

\#5 1 or 2 or 3 or 4

\#6 exp Hemifacial Spasm/

\#7 exp Meige Syndrome/

\#8 exp blepharospasm/

\#9 exp torticollis/

\#10 exp Dystonia/

\#11 exp Dystonic Disorders/

\#12 (cervic\$ adj2 dysto\$).ti,ab.

\#13 blepharosp\$.ti,ab.

\#14 (hem\$ adj2 spasm\$).ti,ab.

\#15 (meige and (dysto\$ or syndrom\$)).ti,ab.

\#16 (crani\$ adj2 dysto\$).ti,ab.

\#17 (foca\$ adj2 dysto\$).ti,ab.

\#18 (write\$ and (cramp\$ or dysto\$)).ti,ab.

\#19 torticol\$̣.ti,ab.

\#20 5 or 6 or 7 or 8 or 9 or 10 or 11 or 12 or 13 or 14 or 15 or 16 or 17 or 18

\#21 exp Botulinum Toxins, Type A/

\#22 exp Botulinum Toxins/

\#23 (botul\$ adj2 tox\$).ti,ab.

\#24 (botox or dysport or xeomin or myobloc or rimabotulinum\$ or abobotuli\$ or onabotulinum\$ or oculinum or purtox or CNBTX or Neuronox).ti,ab.

\#25 21 or 22 or 23 or 24

\#26 19 and 20 and 25

\#27 limit 26 to human

WHAT'S NEW

\begin{tabular}{lll}
\hline Date & Event & Description \\
\hline 6 October 2016 & New search has been performed & $\begin{array}{l}\text { Three new trials enrolling a total of 270 participants were includ- } \\
\text { ed in the meta-analysis and systematic review (Comella 2005; } \\
\text { Pappert 2008; Tintner 2005) }\end{array}$ \\
\hline 9 May 2016 & $\begin{array}{l}\text { New citation required and conclusions } \\
\text { have changed }\end{array}$ & $\begin{array}{l}\text { New authorship, accumulation of changes, reassessment and } \\
\text { writing according to new quality standards, addition of a 'Sum- } \\
\text { mary of findings' table }\end{array}$ \\
\hline
\end{tabular}




\section{H I S T O R Y}

Protocol first published: Issue 3, 2003

Review first published: Issue 1, 2005

\begin{tabular}{lll}
\hline Date & Event & Description \\
\hline 7 October 2008 & Amended & Converted to new review format. \\
\hline 5 May 2003 & $\begin{array}{l}\text { New citation required and conclusions } \\
\text { have changed }\end{array}$ & Substantive amendment \\
\hline
\end{tabular}

\section{CONTRIBUTIONS OF AUTHORS}

A Peter Moore - APM; Cristina Sampaio - CS; Filipe Brogueira Rodrigues - FBR; Gonçalo S Duarte - GSD; João Costa - JC; Joaquim Ferreira - JJF; Mafalda Castelão - MC; Raquel E Marques - REM.

Concieving the review - APM, CS, JC, JJF

Designing the review - APM, CS, JC, JJF

Co-ordinating the review - JC

Designing search strategies - FBR, GSD, JC

Undertaking searches - FBR, GSD

Screening search results - FRB, GSD, MC, REM

Organising retrieval of papers - FRB, GSD, JC, MF, REM

Screening retrieved papers against eligibility criteria - FRB, GSD, MC, REM

Appraising quality of papers - FRB, GSD, JC, MC, REM

Extracting data from papers - FRB, GSD, JC, MC, REM

Writing to authors of papers for additional information - GSD, JC, REM

Data management for the review - FRB, GSD, MC, REM

Entering data into RevMan - FRB, GSD, MC, REM

Analysis of data - FRB, GSD, JC, MC, REM

Interpretation of data - APM, CS, FRB, GSD, JC, JJF, MC, REM

Writing the review - FRB, GSD, JC, MC, REM

GRADE assessment - GSD, JC

Providing general advice on the review - APM, CS, JC, JJF

Performing previous work that was the foundation of the current review - Ana Borges, Claudia Espírito Santo, Miguel Coelho.

\section{DECLARATIONS OF INTEREST}

Costa J, Ferreira JJ, and Sampaio C were investigators in clinical trials in botulinum toxin A and B use in dystonia sponsored by Elan (manufacturer of BtB), Allergan (manufacturer of BtA), and Ipsen (manufacturer of BtA). Searching for studies, selection of studies, data extraction and analysis (including risk of bias), and GRADE assessment were performed by authors (FRB, GSD, MC, REM) that are not trialists. Ferreira JJ and Sampaio C were speakers in symposiums promoted by Elan, Allergan, and Ipsen. 
Moore AP has received royalties from Ipsen for the use 'LIVEchart' scoring system for botulinum toxin treatment efficacy. He has additionally received consulting fees from Ipsen, Merz (manufacturer of BtA), Eisai (manufacturer of BtB), and Allergan. The same companies have provided for support for travel to meetings for studies or other purposes.

\section{SOURCES OF SUPPORT}

\section{Internal sources}

- Cochrane Movement Disorders Group, Portugal.

- The Walton Centre for Neurology and Neurosurgery, UK.

\section{External sources}

- No sources of support supplied

\section{DIFFERENCES BETWEEN PROTOCOLAND REVIEW}

For this updated review the study designs accepted were restricted to parallel-group. No changes were made in the type of participants included or in the interventions allowed.

Adverse events, which were originally a secondary outcome, were included in this updated review as a primary safety outcome. Also, in this safety analysis we considered the proportion of participants with the most frequent adverse events, which was not stated in the original protocol. An assessment of the duration of effect was included as a new secondary outcome measure.

The search strategy was prolonged from the inception to October 2016.

New approaches were assumed to deal with missing data and unit of analysis issues.

The latest recommended Cochrane tool for assessing risk of bias was used in this review, which was expanded to include two additional criteria, added by the review authors. Blinding of outcome assessment was analysed in two new subcategories: subjective and objective assessment.

The trial sequential analysis was not in the original review protocol.

A 'Summary of findings' table was also added.

\section{N DEX TERMS}

\section{Medical Subject Headings (MeSH)}

Botulinum Toxins, Type A [adverse effects] [*therapeutic use]; Dystonia [ ${ }^{\star}$ congenital] [drug therapy]; Neuromuscular Agents [adverse effects] [*therapeutic use]; Randomized Controlled Trials as Topic; Torticollis [ ${ }^{\star}$ drug therapy]

\section{MeSH check words}

Humans 